\title{
NEGOCIACIÓN COLECTIVA Y PREVENCIÓN DE RIESGOS PSICOSOCIALES
}

\author{
Collective bargaining and prevention of psychosocial risks \\ Francisco JaVier Arrieta Idiakez* \\ Universidad de Deusto, España
}

\section{RESUMEN}

El objetivo de este estudio es analizar el tratamiento de los riesgos psicosociales por parte de la negociación colectiva. Para ello, en primer lugar, se define el concepto de riesgo psicosocial y se identifican los distintos tipos de riegos psicosociales. En segundo lugar, se analiza el papel que puede desempeñar la negociación colectiva en la prevención de riesgos psicosociales. En tercer lugar, se analizan 186 convenios colectivos de distinto ámbito, publicados entre enero y diciembre de 2020, con los siguientes objetivos: contrastar si se definen los riesgos psicosociales, observar qué tipos de riegos psicosociales se contemplan y de qué modo y analizar el tratamiento que se da a las distintas rutinas preventivas. Por último, las conclusiones recogen los principales resultados de la investigación.

Palabras clave: riesgos psicosociales, negociación colectiva, convenios colectivos.

\section{ABSTRACT}

The aim of this study is to analyze the treatment of psychosocial risks by collective bargaining. First, the concept of psychosocial risk is defined and the different types of psychosocial risks are identified. Second, the role that collective bargaining can play in preventing psychosocial risks is analyzed. Third, 186 collective agreements of different scope, which have been published between January and December 2020, are analyzed, with the following objectives: contrast if psychosocial risks are defined, observe what types of psychosocial risks are considered and in what way and analyze the treatment given to the different preventive routines. Finally, the conclusions include the main results of the research.

Keywords: psychosocial risks, collective bargaining, collective agreements.

* Correspondencia a: Francisco Javier Arrieta Idiakez. Facultad de Derecho. Universidad de Deusto. Avda. de las Universidades 24 , Bilbao (Bizkaia), España. - javier.arrieta@deusto.es - https://orcid.org/0000-0003-4696-6356

Cómo citar: Arrieta Idiakez, Francisco Javier. (2020) «Negociación colectiva y prevención de riesgos psicosociales»; Lan Harremanak, 44, 238-277. (https://doi.org/10.1387/lan-harremanak.22326).

Recibido: 09 diciembre, 2020; aceptado: 13 diciembre, 2020.

ISSN 1575-7048 - eISSN 2444-5819 / (C) 2020 UPV/EHU 


\section{El concepto de riesgos psicosociales}

En la legislación española no existe una definición del concepto de riesgos psicosociales. No obstante, son varias las definiciones que pueden tomarse en consideración.

Así, la Agencia Europea para la Seguridad y la Salud en el Trabajo (AESST) señala actualmente que:

Los riesgos psicosociales se derivan de las deficiencias en el diseño, la organización y la gestión del trabajo, así como de un escaso contexto social del trabajo, y pueden producir resultados psicológicos, físicos y sociales negativos (https://osha.europa. $\mathrm{eu} / \mathrm{es} /$ themes/psychosocial-risks-and-stress).

Cabe señalar que la Inspección de Trabajo y Seguridad Social (ITSS) define los riesgos psicosociales conforme a una definición previa de la propia AESST (ITSS, 2012: 11):

Aquellos aspectos del diseño, organización y dirección del trabajo y de su entorno social que pueden causar daños psíquicos, sociales o físicos en la salud de los trabajadores.

Además, la ITSS matiza que la referencia a los riesgos psicosociales se centra única y exclusivamente en una de las vertientes del término psicosocial, a saber, la que afecta a la organización de la empresa y su entorno social que es la que corresponde al ámbito de potestades y responsabilidades del empresario (ITSS, 2012: 12).

Por su parte, en la doctrina científica o de autores se ha considerado que (Igartua Miro, 2017: 3):

El riesgo psicosocial es el hecho, acontecimiento, situación o estado que es consecuencia de la organización del trabajo, y tiene una alta probabilidad de afectar a la salud del trabajador y cuyas consecuencias suelen ser importantes.

En todo caso, debe entenderse que solamente tendrán la naturaleza de riesgo psicosocial los factores psicosociales que, adoptando valores desfavorables o adversos, pueden afectar negativamente a la salud (Meliá, Nogareda et al., 2006: 17).

En ese sentido, la NTP 443 del INSHT titulada Factores psicosociales: metodología de evaluación (1997) define los factores psicosociales como:

Aquellas condiciones que se encuentran presentes en una situación laboral y que están directamente relacionadas con la organización, el contenido del trabajo y la realización de la tarea, y que tienen capacidad de afectar tanto al bienestar o a la salud (física, psíquica o social) del trabajador como al desarrollo del trabajo. 
Además, acto seguido, dicha NTP concluye que:

Unas condiciones psicosociales desfavorables están en el origen de la aparición tanto de determinadas conductas y actitudes inadecuadas en el desarrollo del trabajo como de determinadas consecuencias perjudiciales para la salud y para el bienestar del trabajador.

Ahora bien, como recuerda la NTP 604 del INSHT titulada Riesgo psicosocial: el modelo demanda-control-apoyo social (II) (2001), hay que partir de las siguientes tres premisas:

a) Un factor de riesgo es el que incrementa el riesgo de que se produzca un determinado efecto, por ejemplo, una enfermedad.

b) La exposición a factores psicosociales de origen laboral no es un elemento necesario ni imprescindible para que se desarrolle la enfermedad.

c) El efecto puede ser directo, o a través de otros factores de riesgos.

No en vano, la NTP 944 del INSHT titulada Intervención psicosocial en prevención de riesgos laborales: principios comunes (I) (2012) afirma que:

Un factor de riesgo es aquél que incrementa la probabilidad de que ocurra un daño, patología, enfermedad o lesión.

Por ello se ha llegado a matizar que los factores psicosociales no constituyen un riesgo hasta el momento en que se convierten en algo nocivo para el bienestar de la persona trabajadora o cuando desequilibran la relación que este mantiene con el trabajo, con el entorno (Navarro Moros y Salazar Val, 2016, 125).

En consecuencia, es preciso concretar qué factores psicosociales se toman en consideración y, partiendo de los mismos, qué se considera riesgos psicosociales, con el objetivo de identificarlos, evaluarlos y abordarlos a través de la planificación de la actividad preventiva.

Respecto a la primera cuestión, resulta útil la descripción de los factores psicosociales que se recogen en la NTP 926 del INSHT titulada Factores psicosociales: metodología de evaluación (2012). Más concretamente, en la misma, se hace referencia a los factores de tiempo de trabajo, autonomía, carga de trabajo, demandas psicológicas, variedad/contenido, participación/supervisión, interés por el trabajo/compensación, desempeño de rol, y relaciones y apoyo social.

Así es como se reconoce el papel que múltiples aspectos de la organización del trabajo desempeñan sobre la salud de las personas trabajadoras, de forma y manera que ello permite avanzar en la consideración de múltiples factores de riesgo (Arastey Sahún, 2012: 3; Charro Baena, 2012: 16-29). 
De todos ellos, por todo lo antedicho, solamente serán considerados riesgos psicosociales los que tengan una alta probabilidad de causar dańos en la salud de las personas trabajadoras. Se trataría de conductas y actitudes inadecuadas en el desarrollo del trabajo, consecuencia de unas condiciones de trabajo nocivas, que de materializarse desembocarían en determinadas consecuencias perniciosas para la salud y el bienestar de las personas trabajadoras (Romeral Hernández, 2012: 166).

Aunque no haya un consenso unánime sobre la determinación exacta de dichos riesgos, entre otros motivos porque tampoco parece deseable cerrar las puertas a la posibilidad de detectar otros riesgos, en función de la evolución de las distintas formas de interacción entre el medio de trabajo y las personas trabajadoras (Romeral Hernández, 2012: 167) y de que tampoco existe una regulación unitaria sobre esta materia, sí es posible partir de un mínimo consenso respecto a la consideración de algunos riesgos como psicosociales.

Es el caso del estrés laboral, la violencia en el trabajo y la fatiga de las personas trabajadoras derivada de la ordenación del tiempo de trabajo, fundamentalmente del régimen de trabajo nocturno o a turnos (ITSS, 2012:12). También se tiende a considerar como riesgo psicosocial el burnout o síndrome de estar quemado por el trabajo, tras haber sido reconocido por la NTP 732 del INSHT titulada Sindrome de estar quemado por el trabajo "burnout» (III): Instrumento de medición (2006) como uno de los daños laborales de carácter psicosocial más importante, y al referirse la NTP 705 del INSHT titulada Sindrome de estar quemado por el trabajo o burnout» (II): consecuencias, evaluación y prevención (2005) a las graves consecuencias que puede acarrear para la persona trabajadora que padece dicho síndrome. En suma, el burnout es al mismo tiempo un dańo y un riesgo, en tanto en cuanto puede desembocar en otras enfermedades e incluso en la muerte.

Aunque con un menor reconocimiento, debido a su escaso tratamiento, también el INSHT, así como parte de la doctrina de autores (Quirós Hidalgo y Álvarez Cuesta, 2010: 31-33 y 42-45), considera como riesgos psicosociales la ambigüedad y conflicto de rol, el trabajo emocional y la adicción al trabajo.

\section{Concreción de los principales riesgos psicosociales}

Una vez identificados los riesgos psicosociales sobre los que existe consenso, a continuación, se hará una breve aproximación a su conceptualización, a través de la correspondiente fundamentación jurídico-técnica.

\subsection{Estrés laboral}

Comenzando con el estrés laboral, el punto de partida debe ser el Acuerdo marco europeo, de 8 de octubre de 2004, sobre el estrés laboral [SEC (2011) 
0241], dado que el mismo se asumió en el ordenamiento jurídico español en el Acuerdo Interconfederal para la negociación colectiva 2005 (ANC 2005) (BOE de 16 de marzo de 2005).

La definición que se ofrece es la siguiente:

El estrés es un estado que se acompaña de quejas o disfunciones físicas, psicológicas o sociales y que es resultado de la incapacidad de los individuos de estar a la altura de las exigencias o las expectativas puestas en ellos.

Igualmente, son importantes las matizaciones que se realizan al respecto, al afirmar que:

El estrés no es una enfermedad, pero una exposición prolongada al estrés puede reducir la eficacia en el trabajo y causar problemas de salud (...). No todas las manifestaciones de estrés en el trabajo pueden ser consideradas como estrés ligado al trabajo. El estrés ligado al trabajo puede ser provocado por diferentes factores tales como el contenido del trabajo, su organización, su entorno, la falta de comunicación, etc.

La importancia de tales matizaciones radica en que, por una parte, permiten identificar el estrés con la definición de riesgo psicosocial previamente ofrecida, $y$, por otra parte, porque permiten concretar el alcance del estrés en el trabajo, a los efectos de su eventual calificación como riesgo profesional, objeto de prevención por parte del empresario.

Dentro del estrés laboral, y como consecuencia de la utilización de las TIC, dado que estas pueden convertirse en un estresor más, cabe referirse, igualmente, al denominado tecnoestrés, sin perjuicio de que puedan ser susceptibles de ocasionar problemas de distinta índole derivados de su impacto en los puestos de trabajo (Meléndez Morillo-Velarde, 2016: 1). Así, el concepto de tecnoestrés se relaciona con los efectos psicológicos negativos del uso de las TIC y puede ser definido, conforme a la NTP 730 del INSHT titulada Tecnoestrés: concepto, medida e intervención psicosocial (2006), como:

Un estado psicológico negativo relacionado con el uso de TIC o amenaza de su uso en un futuro. Ese estado viene condicionado por la percepción de un desajuste entre las demandas y los recursos relacionados con el uso de las TIC que lleva a un alto nivel de activación psicofisiológica no placentera y al desarrollo de actitudes negativas hacia las TIC.

Además, en la misma NTP 730 del INSHT se matiza que el tecnoestrés alberga diferentes tipos específicos como la tecnoansiedad, la tecnofatiga y la tecnoadicción. Todos ellos se consideran riesgos psicosociales relacionados con el uso de las TIC también en la NTP 1.123 del INSHT titulada Las Tecnologías de la Información y la Comunicación (TIC) III: factores de riesgo psicosocial asociados 
a las nuevas formas de organización del trabajo (2018). Al no darse en esta última una definición de esos distintos tipos de tecnoestrés, siguen siendo válidas las definiciones dadas por la NTP 730 del INSHT.

De este modo, se define la tecnoansiedad como:

El tipo de tecnoestrés más conocido, en donde la persona experimenta altos niveles de activación fisiológica no placentera, y siente tensión y malestar por el uso presente o futuro del algún tipo de TIC. La misma ansiedad lleva a tener actitudes escépticas respecto al uso de tecnologías, a la vez que pensamientos negativos sobre la capacidad y competencia con las TICs.

Como tipo específico de la tecnoansiedad se define la tecnofobia, entendida como aquel tecnoestrés que se focaliza en la dimensión afectiva de miedo y ansiedad hacia las TIC.

Por su parte, se señala que la tecnofatiga se caracteriza:

Por sentimientos de cansancio y agotamiento mental y cognitivo debidos al uso de tecnologías, complementados también con actitudes escépticas y creencias de ineficacia con el uso de TICs.

Como tipo específico de tecnofatiga se menciona la fatiga informativa, entendida como la sobrecarga informativa cuando se utiliza Internet que conlleva la aparición del cansancio mental. En ese sentido, la doctrina científica ha concretado que esta fatiga suele darse en teletrabajadores muy especializados que, por su posición o actividad laboral, tienen que manejar a diario una gran cantidad de información para poder tomar decisiones estratégicas para la empresa (Mella Méndez, 2015: 192).

Por último, se define la tecnoadicción como:

La incontrolable compulsión a utilizar TIC en «todo momento y en todo lugar», y utilizarlas durante largos períodos de tiempo.

\subsection{Burnout o síndrome de estar quemado por el trabajo}

En todo caso, conviene diferenciar el estrés laboral del burnout o síndrome de estar quemado por el trabajo.

El burnout, puede definirse con la NTP 704 del INSHT titulada Sindrome de estar quemada por el trabajo o "burnout» (I): definición y proceso de generación (2005) como:

Una respuesta al estrés laboral crónico integrada por actitudes y sentimientos negativos hacia las personas con las que se trabaja y hacia el propio rol profesional, así como por la vivencia de encontrarse emocionalmente agotado. 
Efectivamente, como recuerda la NTP 732 del INSHT, anteriormente mencionada:

Mientras que el estrés hace referencia a procesos relativamente breves, el burnout es considerado la consecuencia de una situación prolongada de desajuste entre las demandas y los recursos laborales. Además, el burnout implica el desarrollo de actitudes negativas hacia el trabajo y el estrés no necesariamente.

\subsection{Violencia en el trabajo}

Respecto a la violencia en el trabajo, actualmente debe estarse a la definición fijada sobre «violencia y acoso» en el Convenio OIT núm. 190 sobre la violencia y el acoso (2019). Así, se establece en el artículo 1.1.a) que:

La expresión «violencia y acoso» en el mundo del trabajo designa un conjunto de comportamientos y prácticas inaceptables, o de amenazas de tales comportamientos y prácticas, ya sea que se manifiesten una sola vez o de manera repetida, que tengan por objeto, que causen o sean susceptibles de causar, un daño físico, psicológico, sexual o económico, e incluye la violencia y el acoso por razón de género.

Del mismo modo, en el artículo 1.1.b) se matiza que la violencia y el acoso por razón de género incluyen el acoso sexual.

Con fundamento en dicha definición, se reconoce que la violencia y el acoso pueden definirse en la legislación nacional como un concepto único o como conceptos separados. En todo caso, queda claro que siempre deben mantenerse los rasgos que caracterizan a ambos conceptos según el propio Convenio, al disponer el artículo 7 que:

Sin perjuicio del artículo 1 y en consonancia con sus disposiciones, todo Miembro deberá adoptar una legislación que defina y prohíba la violencia y el acoso en el mundo del trabajo, con inclusión de la violencia y el acoso por razón de género.

Sin duda, se trata de una conceptualización novedosa e importante porque, al reconocer que la violencia y el acoso en el mundo del trabajo afectan a la salud psicológica, se reconoce expresamente su carácter de riesgos psicosociales. Concretamente, de ello deriva la prevalencia del elemento objetivo, es decir, el que se pueda causar un dańo, y, en consecuencia, la no necesidad de tener que probar una intencionalidad lesiva o una finalidad discriminatoria (Pons Carmena, 2020: 40). Además, no se requiere reiteración en los comportamientos y prácticas que conducen a la violencia y acoso.

Todo ello conlleva la necesidad de reflexionar sobre los conceptos de acoso y violencia en lugar de trabajo que son de aplicación en España, con el objetivo de saber si se ajustan a los mínimos establecidos por el Convenio OIT núm. 190. 
Comenzando con el concepto de acoso, y dadas las múltiples variantes que presenta en el ordenamiento jurídico español, de entrada, debe considerarse que la definición de acoso discriminatorio que contempla la Ley 62/2003, de 30 de diciembre, de medidas fiscales, administrativas y del orden social (BOE de 31 de diciembre de 2003) no plantea ningún problema por su amplio radio de acción (Martín Valverde, 2009: 123). En concreto, la definición exacta reza como sigue (cfr. artículo 28.1.d):

Toda conducta no deseada relacionada con el origen racial o étnico, la religión o convicciones, la discapacidad, la edad o la orientación sexual de una persona, que tenga como objetivo o consecuencia atentar contra su dignidad y crear un entorno intimidatorio, humillante u ofensivo.

Otro tano debe concluirse para con la definición de acoso por razón de discapacidad que ofrece el Real Decreto Legislativo 1/2013, de 29 de noviembre, por el que se aprueba el Texto Refundido de la Ley General de derechos de las personas con discapacidad y de su inclusión social (BOE de 3 de diciembre 2013) (cfr. artículo 2.f):

Toda conducta no deseada relacionada con la discapacidad de una persona, que tenga como objetivo o consecuencia atentar contra su dignidad o crear un entorno intimidatorio, hostil, degradante, humillante u ofensivo.

En la misma línea, la misma conclusión procede para con las definiciones que tipifica la Ley Orgánica 3/2007, de 22 de marzo, para la igualdad efectiva de mujeres y hombres (BOE de 23 de marzo de 2007) en torno al acoso sexual y al acoso por razón de sexo. Así, se entiende por acoso sexual (cfr. artículo 7.1):

Cualquier comportamiento, verbal o físico, de naturaleza sexual que tenga el propósito o produzca el efecto de atentar contra la dignidad de una persona, en particular cuando se crea un entorno intimidatorio, degradante u ofensivo.

Por su parte, se entiende como acoso por razón de sexo (cfr. artículo 7.2):

Cualquier comportamiento realizado en función del sexo de una persona, con el propósito o el efecto de atentar contra su dignidad y de crear un entorno intimidatorio, degradante u ofensivo.

Sin embargo, no puede concluirse lo mismo respecto al concepto de acoso moral en el trabajo.

De entrada, debe recordarse que en España no existe una definición legal de dicha modalidad de acoso, ni siquiera una referencia a la misma en la legislación laboral, con la excepción del Real Decreto Legislativo 5/2015, de 30 de octubre, por el que se aprueba el texto refundido de la Ley del Estatuto Básico del Em- 
pleado Público (BOE de 31 de octubre de 2015) que se refiere indistintamente al acoso moral y al laboral (cfr. artículos 14.h, 95.2.b y 95.2.o). Con todo, parece que lo correcto es diferenciar en el ámbito laboral dos especies de acoso, a saber, el moral y el sexual, además del acoso discriminatorio (Quirós Hidalgo y Álvarez Cuesta, 2010: 45).

Ahora bien, podría entenderse por acoso moral en el trabajo la definición de acoso que se recoge en el Acuerdo marco europeo, de 26 de abril de 2007, sobre acoso y violencia en el lugar de trabajo [COM (2007) 686 final], y que fue incorporada en España, como sigue, a través de la prórroga para el año 2008 del Acuerdo Interconfederal para la negociación colectiva 2007 (ANC 2007) (BOE de 14 de enero de 2008):

Existe acoso cuando de uno o más trabajadores o directivos, repetida y deliberadamente, se abusa, se les amenaza y/o se les humilla en circunstancias relacionadas con el trabajo.

En el estricto ámbito de la prevención de riesgos laborales también puede mencionarse la NTP 854 del INSHT titulada Acoso psicológico en el trabajo: definición (2009). Aunque prefiera hablarse de acoso psicológico en el trabajo, más que de acoso moral en el trabajo, se considera por tal:

La exposición a conductas de violencia psicológica, dirigidas de forma reiterada y prolongada en el tiempo, hacia una o más personas, por parte de otra/s que actúan frente a aquella/s desde una posición de poder (no necesariamente jerárquica). Dicha exposición se da en el marco de una relación laboral y supone un riesgo importante para la salud.

Pero, principalmente, ha sido la jurisprudencia la que ha elaborado una definición del acoso moral en el trabajo. En ese sentido, cabe destacar la STSJ de Madrid (4.a), de 4 de abril de 2014 (núm. rec. 27/2014), pues, además, de proceder a su definición, se pronuncia sobre los elementos que integran dicha definición, como puede apreciarse a continuación:

«El acoso moral debe tener, siempre, unos perfiles objetivos como son los de la sistematicidad, la reiteración y la frecuencia, requisito este el de la permanencia en el tiempo tradicionalmente aceptado en nuestra doctrina judicial [STSJ del País Vasco (4.a), de 20 de abril de 2002; STSJ de Galicia (4.a), de 8 de abril de 2003; STSJ de Canarias/Las Palmas (4.a), de 28 de abril de 2003] y al propio tiempo, otros subjetivos como son los de la intencionalidad y el de la persecución de un fin. Son, por tanto, elementos básicos de este anómalo proceder humano, de una parte, la intencionalidad o elemento subjetivo, orientado a conseguir el perjuicio a la integridad moral del otro, aunque no se produzca un dańo a la salud mental del trabajador, (el concepto de integridad moral es distinto del de salud) requisito este, siempre exigido en este irregular comportamiento o actitud y, de otra parte, la reiteración de esta 
conducta de rechazo que se desarrolla de forma sistemática durante un período de tiempo. Lo importante es que el comportamiento sea objetivamente humillante, llevando así implícito el perjuicio moral (...).

Con todo (...) la duración o reiteración deberá determinarla el intérprete en cada supuesto concreto, y no resulta imprescindible que quienes acosan lo hagan por una intencionalidad u objetivo, es suficiente [que] los efectos producidos contengan un ataque contra la dignidad de la persona que lo padece o se haya creado un entorno hostil, degradante o humillante.

Lo que caracteriza al acoso moral es, sin duda alguna, la sistemática y prolongada presión psicológica que se ejerce sobre una persona (se le ningunea, hostiga, amilana, machaca, fustiga, atemoriza, amedrenta, acobarda, asedia, atosiga, veja, humilla, persigue o arrincona) en el desempeño de su trabajo, tratando de destruir su comunicación con los demás y atacando su dignidad personal con el fin de conseguir que, perturbada su vida laboral, se aleje de la misma provocando su autoexclusión.

En este orden de ideas, en definición a nuestro modo de ver muy clarificadora, se ha definido doctrinalmente el acoso moral como "comportamientos, actos o conductas llevados a cabo por una o varias personas en el entorno laboral que, de forma persistente en el tiempo, tiene como objetivo intimidar, apocar, amilanar y consumir emocionalmente e intelectualmente a la víctima, con vistas a forzar su salida de la organización o a satisfacer la necesidad patológica de agredir, controlar y destruir que suele presentar el hostigador como medio de reafirmación personal».

El acoso laboral precisa de una efectiva y seria presión psicológica, bien sea esta de un superior o de un compañero - acoso vertical y horizontal- que sea sentida y percibida por el trabajador acosado al que causa un dańo psíquico real que le hace perder la posibilidad de una normal convivencia en su propio ámbito profesional.

Pero no toda actitud de tensión en el desarrollo de la actividad laboral puede merecer el calificativo de acoso moral. Hemos de distinguir lo que es una conducta de verdadera hostilidad, vejación y persecución sistemática de lo que puede ser la exigencia rigurosa de determinado comportamiento laboral, o un ejercicio no regular del poder directivo empresarial, pero que no pretende socavar la personalidad o estabilidad emocional del trabajador.

No puede, en su consecuencia, confundirse el acoso moral con los conflictos, enfrentamientos y desentendidos laborales en el seno de la empresa por defender los sujetos de la relación laboral intereses contrapuestos. El conflicto, que tiene sus propios cauces de solución en el Derecho del Trabajo, es inherente a este, al menos en una concepción democrática y no armonicista de las relaciones laborales $(\ldots)$.

Tampoco el estado de agotamiento o derrumbe psicológico provocado por el estrés profesional, propio de la tecnificación, competitividad en el seno de la empresa, horarios poco flexibles para compatibilizar la vida laboral y familiar, la precariedad del empleo y la falta de estabilidad laboral, debe confundirse con el acoso moral, caracterizado por el hostigamiento psicológico intencionado y reiterado.

$\mathrm{Ni}$ siquiera, con todo lo repudiable que pueda ser, manifestaciones de maltrato esporádico, de sometimiento a inadecuadas condiciones laborales o de otro tipo de violencias en el desarrollo de la relación de trabajo son equiparables al propio y verdadero acoso moral». 
Recientemente, la STC 56/2019, de 6 de mayo, ha establecido una serie de criterios a efectos de valorar la posible vulneración del derecho fundamental a la integridad moral —que desde luego resulta inherente al derecho a no sufrir acoso moral en el trabajo- que confirman el valor de la STSJ de Madrid (4.a), de 4 de abril de 2014, sin perjuicio de que flexibiliza algunos de los elementos definitorios que ofrece la misma. Precisamente, a raíz de esa flexibilización puede decirse que se acerca a la definición ofrecida sobre "violencia y acoso» que contempla el Convenio OIT núm. 190. En efecto, según el TC (F.D. 5.º):

Hay que determinar, atendiendo a las circunstancias del caso, si la conducta enjuiciada es deliberada $\underline{o}$, al menos, está adecuadamente conectada al resultado lesivo (elemento intención); si ha causado a la víctima un padecimiento físico, psíquico o moral $\underline{o}$, al menos, encerraba la potencialidad de hacerlo (elemento menoscabo) y si respondió al fin de vejar, humillar o envilecer o era objetivamente idónea para producir o produjo efectivamente ese resultado (elemento vejación). Faltando este último elemento, no habrá trato «degradante», pero solo podrá descartarse la vulneración del artículo 15 de la Constitución si la conducta enjuiciada halla cobertura legal (legalidad), responde a un fin constitucionalmente legítimo (adecuación), constituye la alternativa menos restrictiva (necesidad) y produce más beneficios sobre otros bienes o valores que perjuicios en el derecho fundamental a la integridad moral (proporcionalidad en sentido estricto).

En efecto, de los extractos que se han subrayado se observa que, en sintonía con la definición ofrecida por el Convenio OIT núm. 190, no es necesario que se llegue a causar un daño y la intencionalidad de dañar no es un requisito imprescindible.

Ahora bien, al margen de tales criterios, el hecho que todas las definiciones sobre el acoso moral en el trabajo que se han mencionado a la luz del ordenamiento jurídico espańol requieran la reiteración en el comportamiento del acosador hace que quiebre la sintonía con la definición del Convenio OIT núm. 190.

Analizada la conceptualización que ofrece el ordenamiento jurídico español sobre el acoso en el trabajo, debe centrarse la atención en la conceptualización que se realiza sobre la violencia en el trabajo.

A tal efecto, nuevamente debe acudirse, por las razones antedichas, a lo dispuesto por el Acuerdo marco europeo, de 26 de abril de 2007, sobre acoso y violencia en el lugar de trabajo. Al respecto, se señala que:

Existe violencia cuando uno o más trabajadores o directivos son agredidos en circunstancias relacionadas con el trabajo.

Si bien conforme a esta definición podría entenderse que la violencia en el lugar de trabajo se refiere a agresiones físicas, en realidad, en sintonía con el 
hecho de que el Convenio OIT núm. 190 define conjuntamente «violencia y acoso", debe superarse esa idea. Es lo que se deduce también de la NTP 489 del INSHT titulada Violencia en el lugar de trabajo (1998), cuando señalar que:

El concepto de violencia debe ser más amplio que el de la mera agresión física (pegar, golpear, empujar, disparar...) y debe incluir y comprender otras conductas susceptibles de violentar e intimidar al que las sufre. Así, la violencia en el trabajo incluiría, además de las agresiones físicas, las conductas verbales o físicas amenazantes, intimidatorias, abusivas y acosantes.

Como puede advertirse, esta noción de violencia en el lugar de trabajo acoge también al acoso. Es decir, sería posible articular también en el ordenamiento jurídico español una definición conjunta para "violencia y acoso», en la línea del Convenio OIT núm. 190.

Igualmente, como advierte la NTP 489 del INSHT, es importante tener en cuenta que el hecho de que un acontecimiento de violencia se produzca en el lugar de trabajo no tiene porqué significar necesariamente que tal suceso sea un resultado directo de la propia actividad laboral. Lo importante es que tal acontecimiento se produzca bajo la premisa de la actividad laboral. Por ello, la NTP 489 del INSHT, acoge los tres tipos de violencia a los que se refiere la California Division of Occupational Health and Safety (Cal/OSHA), atendiendo a quiénes son las personas implicadas y el tipo que las relaciona entre sí. De este modo, el primer tipo de violencia se produce cuando la persona trabajadora sufre la violencia producida por personas que no tienen con ella ninguna relación de trato, como sucede con las acciones relacionadas con los robos. En el segundo tipo de violencia existe algún tipo de relación profesional entre el causante del acto violento y la víctima, de forma y manera que los hechos violentos se producen mientras que la víctima ofrece el correspondiente servicio. En el tercer tipo de violencia el causante de la violencia mantiene algún tipo de implicación laboral con el lugar afectado o con alguna persona trabajadora de tal lugar.

\subsection{Fatiga de las personas trabajadoras}

La fatiga de las personas trabajadoras es la que se vincula a la ordenación del tiempo de trabajo, ya sea bien por exceso de tiempo de trabajo o por la falta del descanso. Suele manifestarse principalmente en los trabajos nocturnos o a turnos, así como en las situaciones de reiterada prolongación de la jornada laboral o falta del debido descanso interjornadas (ITSS, 2012:14).

Así pues, la estructura temporal del trabajo se convierte en el elemento esencial, pues la fatiga trae causa de su organización inadecuada. Al respecto, la norma ISO 10075, titulada Principios ergonómicos relacionados con la carga de trabajo mental (1991), define el término fatiga como sigue: 
La alteración temporal de la eficiencia funcional de la persona. Esta alteración es función de la actividad previa (esfuerzo mental realizado: atención, concentración, memoria, etc.) y de su estructura temporal.

En todo caso, tal y como advierte la NTP 732 del INSHT titulada Sindrome de estar quemado por el trabajo «burnout» (III): Instrumento de medición (2006), debe diferenciarse la fatiga del burnout, pues:

La recuperación de la fatiga por parte del trabajador es relativamente rápida, mientras que la recuperación del burnout es mucho más lenta y costosa emocionalmente (...). La fatiga suele ir acompañada de sentimientos de competencia y realización personal, mientras que el burnout conlleva una auto-evaluación negativa y sentimiento de ineficacia laboral.

Centrando la atención en los trabajos nocturnos y a turnos, para comprender la fatiga que pueden producir si no se organizan correctamente, conviene tener en cuenta los inconvenientes que presentan, precisamente, para que puedan diseñarse de manera que sean lo menos nocivo posibles para la salud de las personas trabajadoras afectadas. Para ello resulta interesante la toma en consideración de la NTP 455 del INSHT titulada Trabajo a turnos y nocturno: aspectos organizativos (1997), pues al referirse a los inconvenientes de estas modalidades de trabajo, por una parte, se señala que en los mismos se ve alterado el equilibrio biológico, por el desfase de los ritmos corporales y por los cambios en los hábitos alimentarios, $\mathrm{y}$, por otra parte, se advierte de las perturbaciones en la vida familiar y social. Más concretamente, en lo referente al equilibrio biológico se llama la atención sobre las consecuencias de alterar el sueño, al señalar que:

En el turno de mañana, al tener que despertarse demasiado pronto y acortar las últimas horas de sueño, se reduce el sueño paradójico, mientras que en el turno de noche, al alterar el ritmo sueño/vigilia, y a causa de la mayor dificultad de dormir de día (...) se observa una reducción del sueño profundo, con lo que se dificulta la recuperación de la fatiga física.

Por consiguiente, la falta de descanso constituye la principal causa de la fatiga. Así se reconoce, por ejemplo, en la NTP 445 del INSHT titulada Carga mental de trabajo: fatiga (1997), al afirmar que:

La fatiga provocada por el trabajo es una manifestación (general o local) de la tensión que este produce y suele eliminarse mediante un adecuado descanso.

En la misma línea, también debe destacarse la NTP 916 del INSHT titulada El descanso en el trabajo (I): pausas (2011), en primer lugar, porque profundiza en la idea de que el descanso es consustancial al trabajo. En segundo lugar, porque estructura la fatiga laboral en tres tipos, a saber: 
a) La fatiga física o biomecánica: derivada de los esfuerzos musculares, de la posición de trabajo, de los movimientos repetitivos y del manejo manual de cargas.

b) La fatiga psíquica: deriva principalmente de la sobrecarga mental del trabajo, o sea, de la presión en el trabajo y todo lo que comporte estrés, la carga mental propiamente dicha por el procesamiento continuado de información, y, finalmente, las tensiones derivadas de la organización del trabajo y las relaciones laborales. Igualmente, forman parte de este tipo de fatiga la rutina y la falta de autonomía y contenido del trabajo.

c) La fatiga derivada de las condiciones ambientales adversas, fundamentalmente por agentes físicos: ruido, vibraciones, radiaciones, calor, frío e iluminación.

La conclusión de la NTP 916 del INSHT se centra en la importancia de las pausas y del descanso, al señalar que:

Una de las principales causas de la acumulación de fatiga es la falta de pausas, siendo muy importante tanto en cantidad (importancia del conocimiento de los tiempos de reposo) según el esfuerzo efectuado, como en calidad (diseńo de los espacios), es decir, la fatiga es un mecanismo de defensa del organismo que nos indica que debemos descansar.

Como ha podido observase la carga mental se incluye en la fatiga, en su modalidad psíquica. Sin embargo, debido a las importantes particularidades que presenta, el INSHT le ha dedicado una especial atención.

De este modo, la NTP 179 del INSHT titulada La carga mental del trabajo: definición y evaluación (1986), diferencia la carga mental de la carga física, al senalar que:

La carga mental está determinada por la cantidad y el tipo de información que debe tratarse en un puesto de trabajo. Dicho de otro modo, un trabajo intelectual implica que el cerebro recibe unos estímulos a los que debe dar respuesta, lo que supone una actividad cognitiva.

En la misma línea, la NTP 544 del INSHT titulada Estimación de la carga mental de trabajo: el método NASA TLX (2000) define la carga mental como:

La cantidad de esfuerzo deliberado que debemos realizar para conseguir un resultado concreto.

Es la NTP 445 del INSHT titulada Carga mental de trabajo: fatiga (1997) la que define la fatiga mental como: 
La alteración temporal (disminución) de la eficiencia funcional mental y física; esta alteración está en función de la intensidad y duración de la actividad precedente y del esquema temporal de la presión mental.

Por su parte la NTP 534 del INSHT titulada Carga mental del trabajo: factores (1999), es de gran ayuda de cada a considerar los factores que pueden conllevar a la carga menta, y, por ende, a la fatiga psíquica, como riesgo psicosocial. Se parte de la circunstancia de que en cada trabajo los factores que contribuyen a la carga de trabajo mental y que ejercen presiones sobre la persona que lo desempeña son muy diversos. Además, se recuerda que tales factores deben identificarse para cada puesto o situación de trabajo concreta. Por ello, se agrupan los factores según procedan de las exigencias de la tarea, de las circunstancias de trabajo (físicas, sociales y de organización), del exterior de la organización. Así, se llega a la conclusión de que:

La carga de trabajo mental puede ser inadecuada cuando uno o más de los factores identificados es desfavorable y la persona no dispone de los mecanismos adecuados para afrontarlos.

En cualquier caso, se advierte que las características individuales influyen en la tensión que provocan en la persona las distintas presiones que recaen sobre ella. Concretamente, se consideran características individuales el nivel de aspiración, la autoconfianza, la motivación, las actitudes y los estilos de reacción; las capacidades, la cualificación/capacitación, los conocimientos y la experiencia; la edad, el estado general, la salud, la constitución física y la nutrición; y el estado real y el nivel inicial de activación.

\subsection{Ambigüedad y conflicto de rol}

El riesgo psicosocial de la ambigüedad y conflicto de rol, como manifiesta su propia denominación, se integra de dos elementos que deben diferenciarse. A tal efecto resulta aclarativa la NTP 388 del INSHT titulada Ambigüedad y conflicto de rol (1995).

Así, respecto la ambigüedad de rol se establece que:

Se refiere a la situación que vive la persona cuando no tiene suficientes puntos de referencia para desempeñar su labor o bien estos no son adecuados. En definitiva, dispone de una información inadecuada para hacerse una idea clara del rol que se le asigna, bien por ser incompleta, bien por ser interpretable de varias maneras, o bien por ser muy cambiante (...). Tal información debería tratar sobre el propósito u objetivos de su trabajo, su autoridad y sus responsabilidades, su estilo de relación y comunicación con los demás, etc. 
Sus manifestaciones como riesgo psicosocial se relacionan con mayor tensión y descontento en el trabajo, baja autoestima, ansiedad y algunos síntomas de depresión. Al mismo tiempo puede ser fuente de estrés.

En cambio, el conflicto de rol se produce cuando hay demandas, exigencias en el trabajo que son entre sí incongruentes o incompatibles para realizar el trabajo. Especial atención merece para la NTP 388 del INSHT, como origen del conflicto de rol, la existencia de distintos roles en una misma persona y la imposibilidad de compatibilizarlos adecuadamente, dando lugar a lo que se denomina «sobrecarga de rol», es decir, que las demandas del conjunto de roles que desempeña una misma persona entran en conflicto con el tiempo de que dispone y, por ello, exceden su capacidad de respuesta, ya sea debido al excesivo número de tareas requeridas o a la naturaleza de las mismas. Por ello, se afirma que, de no llevarse a cabo un ajuste, jerarquizando con algún criterio los distintos roles, puede surgir una situación insatisfactoria, que se vive como un conflicto de roles.

\subsection{Trabajo emocional}

El trabajo emocional, como riesgo psicosocial puede definirse como (Martínez Ińigo, 2001: 138):

Aquellos procesos psicológicos y conductas, conscientes y/o automáticas, que se derivan de la existencia de normas organizacionales sobre la expresión emocional, sobre la experiencia emocional o sobre ambas, que regulan las distintas interacciones implicadas en el desempeño de un puesto y que pretenden facilitar la consecución de objetivos organizacionales sobre la expresión emocional asociados con el logro de otros objetivos, operativos y/o simbólicos, de mayor orden.

Se trata de una definición que asume para sí la NTP 720 del INSHT titulada El trabajo emocional: concepto y prevención (2006), y que resume como sigue:

El trabajo (o esfuerzo) emocional realizado por el empleado en su trabajo responde a demandas emocionales concretas, que vienen reguladas por un conjunto de normas organizacionales sobre cómo debe comportarse el empleado en su interacción con el cliente/usuario.

La NTP 720 del INSHT vincula directamente este riesgo psicosocial al sector servicios, al entender que en los trabajos de prestación de servicios las personas trabajadoras no solo deben realizar tareas físicas o mentales, sino que también deben expresar emociones durante las interacciones que realizan cara a cara (o voz a voz, si es por teléfono) con sus receptores del servicio. Así, durante esas interacciones intentan crear ciertas impresiones, mostrando las emociones «apropiadas» para la situación o para que su imagen no se vea amenazada. 
Entre las implicaciones que conlleva el trabajo emocional se destaca que puede producir burnout, pero también la alienación y extrañamiento del yo, es decir, tener problemas para distinguir cuando es uno mismo o cuando está simulando o, incluso, producir interferencia con la ejecución de roles privados, dificultad para desconectar y regular emociones en el ámbito privado, así como dolencias psicosomáticas.

\subsection{Adición al trabajo}

La adicción al trabajo se define por la NTP 759 del INSHT titulada La adicción al trabajo (2007) como:

Un daño psicosocial caracterizado por el trabajo excesivo debido fundamentalmente a una irresistible necesidad o impulso de trabajar constantemente.

Además, se matiza que esta adicción no termina cuando acaba la jornada de trabajo, sino que supone que el adicto al trabajo se lleve trabajo a casa, trabaje los fines de semana, durante las vacaciones e incluso estando enfermo, y que aun sin estar trabajando esté pensando en temas laborales.

Las principales características de las personas adictas al trabajo se identifican en la alta importancia y significado que presenta el trabajo para las mismas; en su alta vitalidad, energía y competitividad; en trabajar más de lo exigido; en el alto nivel de control sobre su trabajo sin capacidad para delegar; en la comunicación interpersonal deficiente; y en la vinculación de su autoestima a los resultados positivos de su trabajo.

Las consecuencias de la adicción al trabajo se consideran un daño psicosocial, pues conlleva consecuencias negativas para la persona del trabajador como ansiedad, conductas compulsivas y el aislamiento social.

\section{El papel de la negociación colectiva en la prevención de riesgos psicosociales}

El papel de la negociación colectiva en la prevención de riesgos laborales, en general, y de los riesgos psicosociales en particular, consiste en el desarrollo y complemento de la Ley 31/1995, de 8 de noviembre, de prevención de riesgos laborales (LPRL) (BOE de 10 de noviembre de 1995), con fundamento en su artículo 1 (Botana López, 1997: 29). Más allá de esta evidencia normativa, se considera que la negociación colectiva constituye un marco idóneo de regulación de cuestiones que tienen que ver con las condiciones de seguridad y salud laboral (Goñi Sein, 2013, 45).

En todo caso, el carácter de Derecho necesario mínimo indisponible que declara el artículo 2 de la LPRL, no solo de la propia LPRL, sino que también de 
sus reglamentos, hace que el nivel de protección resultante de esta normativa no pueda ser reducido mediante la negociación colectiva (Botana López, 1997: 33).

De ahí que la negociación colectiva también pueda cumplir una importante función de mejora. En último término, la negociación colectiva constituye una institución dinámica y una herramienta apropiada para asimilar y adaptar permanentemente los cambios en la organización del trabajo y los riesgos que la misma conlleva, facilitando así la sensibilidad por la prevención de riesgos psicosociales, la información y formación en torno a los mismos y la participación de los representantes de las personas trabajadoras en su organización y gestión (Mercader Uguina y Muñoz Ruiz, 2002: 2-3, 9-10 y 16-18; Romeral Hernández, 2012: 165).

En ese sentido, la negociación colectiva puede identificar los posibles riesgos psicosociales para su evaluación en el ámbito de aplicación del correspondiente convenio colectivo, precisamente, en función de las características que son propias en cada sector e incluso en cada empresa. Se trata de que la negociación colectiva ponga las condiciones para que estos riesgos se evalúen (Charro Baena, 2012: p. 25; Triguero Martínez, 2019: 59).

Los fundamentos jurídicos para ello se encuentran en distintos preceptos de la LPRL y del Real Decreto 39/1997, de 17 de enero, por el que se aprueba el Reglamento de los Servicios de Prevención (RSP) (BOE de 31 de enero de 1997), así como en otras normas que se comentan a continuación:

a) El artículo 4 de la LPRL establece que la prevención tiene por finalidad evitar o disminuir los riesgos derivados del trabajo, entendiendo por tales los que puedan ocasionar a las personas trabajadoras un determinado daño derivado del trabajo. Se especifica que tienen la consideración de daños derivados del trabajo las enfermedades, patologías o lesiones sufridas con motivo u ocasión del trabajo. Al respecto, cobra especial importancia la definición que se da de condición de trabajo, pues se entiende por tal cualquier característica del mismo que pueda tener una influencia significativa en la generación de riesgo para la seguridad y la salud de las personas trabajadoras. Además, se incluyen específicamente en dicha definición todas aquellas características del trabajo, incluidas las relativas a su organización y ordenación, que influyan en la magnitud de los riesgos a que esté expuesto la persona trabajadora.

No cabe duda de que los riesgos psicosociales pueden ocasionar un dańo derivado del trabajo, en la medida en que el propio trabajo es el origen del riesgo, $y$, más concretamente, la forma en la que se organiza el mismo.

De ahí deriva que la evaluación de los riesgos psicosociales deba centrarse en el análisis de las condiciones de trabajo de carácter psicosocial, 
para lo que resulta esencial concretar previamente los riesgos psicosociales que puedan darse en cada sector y/o empresa.

b) Una vez identificados los correspondientes riesgos psicosociales, en virtud del artículo 14 de la LPRL el empresario tiene el deber de proteger a las personas trabajadoras de tales riesgos, en tanto en cuanto son riesgos laborales. No cabe duda de que los riesgos psicosociales constituyen riesgos laborales porque el apartado 2 de dicho precepto dispone que, en cumplimiento del deber de protección, el empresario debe garantizar la seguridad y salud de las personas trabajadoras a su servicio en todos los aspectos relacionados con el trabajo. Concretamente, se establece que dicha protección debe llevarse a cabo por el empresario a través de la prevención de riesgos laborales para lo que deberá integrar la actividad preventiva en la empresa y adoptar cuantas medidas sean necesarias.

c) El empresario, para prevenir los riesgos laborales debe aplicar las distintas técnicas o ciencias de prevención (actividades preventivas), entre las que se encuentra la Psicosociología, técnica no médica cuyo objetivo es prevenir y corregir la insatisfacción en el trabajo como fuente de riesgos (Viñas Armada, 2007: 22). Su materialización también puede concretarse vía negociación colectiva, pero, en todo caso, deben respetarse los principios de la acción preventiva a los que se refiere el artículo 15 de la LPRL, entre los que se encuentra, precisamente, el principio de evaluación. Este principio parte de que los riesgos que no pueden evitarse han de ser evaluados, es decir, analizados y jerarquizados conforme a la probabilidad y peligrosidad, tanto al comienzo de la actividad, como periódicamente, y siempre teniendo en cuenta la evolución de la técnica.

d) El artículo 3 del RSP desarrolla el principio de evaluación, al establecer que la evaluación de los riesgos laborales es el proceso dirigido a estimar la magnitud de aquellos riesgos que no hayan podido evitarse, obteniendo la información necesaria para que el empresario esté en condiciones de tomar una decisión apropiada sobre la necesidad de adoptar medidas preventivas y, en tal caso, sobre el tipo de medidas que deben adoptarse. El empresario está obligado a consultar a los representantes de los trabajadores acerca del procedimiento de evaluación a utilizar. Ello, no obstante, la negociación colectiva puede ir más allá de la mera consulta y convertirse en un medio para fijar el método de evaluación adecuado de los riesgos psicosociales (Romeral Hernández, 2012: 183). Respecto a la elección de los métodos de evaluación debe considerarse, además, lo preceptuado en el artículo 5.3 del Real Decreto 39/1997, pues abre las puertas a la toma en consideración de métodos y criterios fijados en Normas UNE, Guías del INSHT o ins- 
tituciones competentes de las Comunidades Autónomas, normas internacionales e incluso, vía artículo 5.2, en las propias NTP del INSHT.

e) El III Acuerdo para el Empleo y la Negociación Colectiva 2015, 2016, 2017 (BOE de 20 de junio de 2015), prorrogado por el IV Acuerdo para el Empleo y la Negociación Colectiva (BOE de 18 de julio de 2018), resulta útil para reconocer como riesgos psicosociales el estrés laboral y la violencia en el trabajo. Además, se remite a los contenidos sobre ambos riesgos que recogen el Acuerdo marco europeo, de 8 de octubre de 2004, sobre el estrés laboral y el Acuerdo marco europeo, de 26 de abril de 2007, sobre acoso y violencia en el lugar de trabajo (supra 2), al establecer que tales contenidos debieran servir de referencia cuando se aborden estas materias en los convenios.

f) El artículo 46.2 de la Ley Orgánica 3/2007, de 22 de marzo, para la igualdad efectiva de mujeres y hombres (BOE de 23 de marzo de 2007) establece que el diagnóstico negociado con la representación legal de las personas trabajadoras que debe realizarse como soporte de los planes de igualdad, debe contener, entre otras materias, la prevención del acoso sexual y por razón de sexo. Por su parte, el artículo 7.1 del Real Decreto 901/2020, de 13 de octubre, por el que se regulan los planes de igualdad y su registro y se modifica el Real Decreto $713 / 2010$, de 28 de mayo, sobre registro y depósito de convenios y acuerdos colectivos de trabajo (BOE de 14 de octubre de 2020), tras señalar que el resultado del proceso de toma y recogida de datos en que consiste el mencionado diagnóstico constituye la primera fase del plan de igualdad, se centra en la importancia de dicho diagnóstico, al afirmar que el mismo permite obtener la información precisa para diseñar y establecer las medidas evaluables que deben adoptarse, la prioridad en su aplicación y los criterios necesarios para evaluar su cumplimiento. Precisamente, un resumen del análisis realizado y de sus principales conclusiones y propuestas debe incluirse en un informe que formará parte del plan de igualdad. Es más, el artículo 8 del Real Decreto 901/2020 no solo incide en que el plan de igualdad debe contener las medidas que resulten necesarias en virtud de los resultados del diagnóstico, sino que también permite que se incorporen en el mismo medidas relativas a materias no enumeradas en el artículo 46.2 de la Ley Orgánica 3/2007. Igualmente, importante resulta el Anexo que contiene el Real Decreto 901/2020, bajo la rúbrica «Disposiciones aplicables para la elaboración del diagnóstico», porque fija los criterios que deben cumplirse al elaborar el diagnóstico. Pero, sobre todo, y lo que es más importante, establece que el procedimiento de actuación frente al acoso sexual y por razón de sexo formará parte de la nego- 
ciación del plan de igualdad. Es más, se fija el contenido que, en todo caso, deben contemplar los procedimientos de actuación:

- Declaración de principios, definición de acoso sexual y por razón de sexo e identificación de conductas que pudieran ser constitutivas de acoso.

- Procedimiento de actuación frente al acoso para dar cauce a las quejas o denuncias que pudieran producirse, y medidas cautelares y/o correctivas aplicables.

- Identificación de las medidas reactivas frente al acoso y en su caso, el régimen disciplinario.

Por todo ello, el papel de la negociación colectiva a la hora de concretar todos esos contenidos resulta una vez más esencial.

Pero más allá de prevención del acoso sexual y por razón de sexo, como riesgos psicosociales perfectamente identificados, la negociación colectiva en general, y los planes de igualdad, en particular, se convierten en una herramienta de gran alcance para integrar la dimensión de la igualdad entre hombres y mujeres como elemento a ser evaluado para prevenir también otros riesgos psicosociales que afectan, muy especialmente, a las mujeres. En último término, se trata de que el factor género no quede desatendido en el marco de la prevención de riesgos laborales. No en vano, la Estrategia Española de Seguridad y Salud en el Trabajo 2015-2020 consagra el principio de especificidad por razón de sexo en las políticas preventivas, cuando, al referirse a las personas trabajadoras vulnerables y a los colectivos específicos, señala que:

La creciente incorporación de la mujer al trabajo en las últimas décadas hace necesario promover un enfoque de género en las actividades preventivas, que permita detectar particularidades y garantizar su protección.

Del mismo modo, dentro de las líneas de actuación y medidas propuestas, dicha Estrategia, al referirse a la promoción de la seguridad y salud de colectivos específicos de personas trabajadoras, recoge expresamente la necesidad de:

Impulsar la integración de aspectos de género en la actividad preventiva, especialmente en sectores con mayor presencia de la mujer.

En concreto, los elementos a considerar desde la perspectiva de género en la evaluación de riesgos psicosociales serían, principalmente, los relacionados con las características del empleo (mayores niveles de contratos parciales y temporales), los trabajos desempeñados (segregación de tareas horizontal y vertical, menores salarios, posibilidades de promoción y formación) y características de la vida extralaboral (mayor realización de trabajo doméstico) [Ficha Técnica de 
Prevención 35 del Instituto Navarro de Salud Laboral (INSL) titulada Mujeres y Salud Laboral. Prevención de riesgos laborales desde la perspectiva de género. Propuestas de intervención (2011); Grau Pineda, 2017: 37-42)].

En suma, la evaluación psicosocial se convierte en un instrumento de diagnóstico sobre la igualdad de trato y no discriminación, de forma y manera que ambas acciones preventivas quedan integradas (Velázquez Fernández, 2019: 148).

Identificados, definidos y evaluados los correspondientes riesgos psicosociales debe procederse al cumplimiento del resto de principios de acción preventiva contemplados en el artículo 15 de la LPRL, entre los que deben destacarse los siguientes:

a) Combatir los riesgos en su origen: la negociación colectiva puede jugar un papel importante al contemplar los correspondientes protocolos de actuación y medidas disuasorias.

b) Adaptar el trabajo a la persona, en particular en lo que respecta a la concepción de los puestos de trabajo, así como a la elección de los equipos y los métodos de trabajo y de producción, con miras, en particular, a atenuar el trabajo monótono y repetitivo y a reducir los efectos del mismo en la salud. Se trata de un principio que la negociación colectiva puede concretar en todo caso de cara a los riesgos psicosociales, pero, sobre todo, en los trabajos a turnos y nocturnos, y en los trabajos a distancia. Igualmente, en la medida en que la toma en consideración de la perspectiva de género en la aplicación de este principio es fundamental para evitar las resultas de los riesgos psicosociales vinculados al sesgo de género (Vallejo da Costa, 2014: 37), la negociación colectiva puede jugar un papel importante al establecer las medidas encaminadas, por ejemplo, a la conciliación de la vida personal, familiar y laboral, a la promoción de la contratación indefinida y a tiempo completo en condiciones de igualdad y a garantizar la promoción interna en términos de igualdad material.

c) Planificar la prevención, buscando un conjunto coherente que integre en ella la técnica, la organización del trabajo, las condiciones de trabajo, las relaciones sociales y la influencia de los factores ambientales en el trabajo. En virtud de lo establecido en los artículos 18.2 y 34 y siguientes de la LPRL, la participación de las personas trabajadoras al respecto se convierte en un derecho, que de ser encauzado debidamente a través de la negociación colectiva es la mejor manera de integrar la prevención en la empresa, facilitando la colaboración de las personas trabajadoras en la adopción y cumplimiento de las medidas preventivas. Además, a tenor de lo dispuesto en la Disposición Transitoria primera de la LPRL, la negociación colectiva puede servir para 
dotar de sentido y alcance a la participación de las personas trabajadores en la planificación de la prevención. Por ejemplo, pueden delimitarse las funciones y competencias de los representantes unitarios en materia de prevención de cara a la implementación de medidas preventivas en colaboración con el empresario, así como para la vigilancia y control de su cumplimiento; con fundamento en el artículo 35.4 de la LPRL puede establecerse un sistema alternativo de designación de delegados de prevención, de forma y manera que en las empresas que no cuenten con órganos de representación unitaria pueda designarse también a tales delegados, dotándoles de funciones y competencias, así como de suficiente dedicación; pueden incrementarse las funciones y facultades consultivas del comité de seguridad y salud laboral; o pueden crearse órganos específicos de representación paritaria en materia de riesgos psicosociales (Goñi Sein, 2013, 48-50).

d) Dar las debidas instrucciones a las personas trabajadoras. La forma en la que se informa y forma también puede encauzarse a través de la negociación colectiva. En este sentido, aunque limitado a las medidas y protocolos para prevenir el acoso sexual y por razón de sexo, es de interés el depósito que al respecto prevé, aunque con carácter voluntario, el Real Decreto 901/2020 (cfr. artículo 12). El mismo puede servir de difusión de buenas prácticas entre las empresas; buenas prácticas que, posteriormente, pueden tenerse en cuenta en la negociación colectiva. En la misma dirección, las medidas que se adopten, vía negociación colectiva, tras el diagnóstico a realizar de cara a los planes de igualdad, siempre que se informe adecuadamente de las mismas a las personas trabajadoras y se forme debidamente a estas, pueden ayudar a prevenir los riesgos psicosociales. Todo ello posibilita la integración plena de los riesgos psicosociales en las rutinas preventivas de cada empresa.

Todas estas rutinas requieren, asimismo, de la denominada organización preventiva. Respecto a la misma, la negociación colectiva constituye una vía importante para que dicha organización se realice de forma directa por las propias empresas mediante la asunción de las actividades preventivas. Es lo que viene a corroborar la Disposición Adicional séptima del Real Decreto 39/1997, cuando posibilita a la negociación colectiva establecer criterios para la determinación de los medios personales y materiales de los servicios de prevención propios.

Dentro de las rutinas preventivas también debe destacarse la relevancia que puede tener la negociación colectiva en cuanto a la vigilancia de la salud de las personas trabajadoras frente a las consecuencias de los riesgos psicosociales. En efecto, con fundamento en el artículo 22.1 de la LPRL, es perfectamente posible establecer reconocimientos médicos obligatorios para prevenir las resultas de los riesgos psicosociales en la salud de las personas trabajadoras. En verdad, la rea- 
lización de tales reconocimientos resulta imprescindible para evaluar los efectos de las condiciones de trabajo sobre la salud de las personas trabajadoras.

Por último, dado que las fases preventivas deben culminar con una auditoría, como instrumento de evaluación de todo el proceso de implantación del sistema de prevención y, en particular, de la eficacia del modelo organizativo adoptado, la negociación colectiva puede regular el modelo de auditoría a llevar cabo, principalmente cuando se apueste por una auditoría interna. Asimismo, la negociación colectiva puede prever mecanismos de compliance laboral con el objetivo de llevar a cabo una labor de prevención de los riesgos que conlleva el incumplimiento de medidas preventivas en materia de riesgos psicosociales (Rojas Rosco, Moraleja Moraleja y Gutiérrez Arranz, 2017: 24).

\section{Análisis del tratamiento otorgado por los convenios colectivos más recientes a la prevención de los riesgos psicosociales}

Una vez concretado el significado de riesgo psicosocial, identificados los principales riesgos psicosociales y sentadas las bases jurídico-técnicas respecto al papel que puede jugar la negociación colectiva en la prevención de riesgos psicosociales, en este apartado se procederá a describir el tratamiento otorgado por los convenios colectivos más recientes a la prevención de riesgos psicosociales, con el fin de poder extraer las conclusiones pertinentes (infra 5). En concreto, se han analizado 186 convenios colectivos de distinto ámbito publicados en los correspondientes boletines oficiales desde el 1 de enero de 2020 hasta comienzos de diciembre de ese mismo año.

Dicho análisis partirá de un estudio que gira en torno a saber de qué manera se concretan en los convenios colectivos los riesgos psicosociales. A continuación, se pretende observar si se contempla y en qué términos la protección frente a los mismos. Finalmente, en íntima conexión con dicha protección, y de cara a materializarla, se centrará la atención en la evaluación de los riesgos psicosociales y en la importancia que a los mismos dedica la organización de la prevención.

\subsection{Concreción de riesgos psicosociales}

Los riesgos psicosociales que se concretan y abordan de distinta manera en los distintos convenios colectivos son el acoso psicológico o moral, el acoso sexual, el acoso por razón de sexo, orientación sexual o identidad de género, el acoso discriminatorio, cualquier forma de violencia en el lugar de trabajo y la fatiga. Es más, algún convenio colectivo, como el Convenio colectivo provincial del sector de la construcción de Pontevedra (BOPPO de 21 de septiembre de 2020) (cfr. artículo 43) y el Convenio colectivo provincial del sector de mármoles y piedras de Pontevedra (BOPPO de 21 de septiembre de 2020) (cfr. artículo 
11.2) se refieren a los mismos bajo la rúbrica de «riesgos psicosociales». Por todo ello, a continuación, se analizarán los aspectos más relevantes que se contienen sobre estos riesgos psicosociales en los distintos convenios colectivos.

\section{a) Acoso psicológico o moral}

Esta modalidad de acoso se contempla en los convenios colectivos con distinto alcance. Incluso aparece con la denominación genérica de acoso laboral.

En ocasiones existe una mera definición a los efectos de vigilancia y control, como es el caso del Convenio colectivo de la provincia de Sevilla para las actividades de almacenistas de hierros, tuberías, aceros y material no férreo (BOPS de 8 de junio de 2020) (cfr. Disposición Adicional 5. a) o del Convenio colectivo estatal de centros y servicios veterinarios (BOE de 14 de agosto de 2020) (cfr. artículo 65).

El Convenio colectivo de Globalia Handing (BOE de 13 de mayo de 2020) (cfr. artículo 41), tras definir el acoso moral, matiza que este no debe confundirse con otras figuras como el burnout o síndrome del quemado en el trabajo, el estrés, la fatiga mental, etc. Además, define el burnout como el estado de agotamiento físico, emocional y mental causado por estar implicado el trabajador durante largos períodos de tiempo en situaciones que le afectan emocionalmente.

Además de la definición, a veces se concretan las conductas que se consideran constitutivas de acoso moral, como sucede en el Convenio colectivo de Hertz de España, SL (BOE de 7 de enero de 2020) (cfr. artículo 54).

Algunos convenios sectoriales crean una comisión de trabajo en el seno de su comisión paritaria con el objetivo de acordar un protocolo que reglamente un procedimiento especial para tratar el acoso moral. Así sucede en el II Convenio colectivo de Compañía Española de Petróleos, SA, para sus refinerías de San Roque (Cádiz); La Rabida (Huelva) y Santa Cruz de Tenerife (BOE de 6 de octubre de 2020) (cfr. Disposición Transitoria tercera).

Otros convenios, como el Convenio colectivo del Grupo Bebidas Naturales (Bebidas Naturales, SL, Aguas de Cortes, SA, Agua de Bronchales, SA, Fuente Arevalillo, SL y Font Teix, SA) (BOE de 1 de agosto de 2020) (cfr. artículo 33) o el Convenio colectivo de Ahorramas, SA; Comercial Hermanos Vallejo, SA; Comercial Monte Igueldo, SL; Comercial Sierra, SL; J y M 44, SA; Majuan, SL; Monelja, SL; Rotterdam, SL y Rubio Martín, SL (BOE de 1 de agosto de 2020) (cfr. Anexo II), regulan expresamente un protocolo contra el acoso moral, diferenciado del protocolo contra el acoso sexual o por razón de sexo que se incorpora al plan de igualdad, en el que se recogen la definición, las normas de comportamiento para evitarlo y un procedimiento interno.

Pero también existen convenios colectivos que regulan un mismo protocolo para todo tipo de acoso, como es el caso del Convenio colectivo de Control y 
Montajes Industriales CYMI, SA (BOE de 7 de enero de 2020) (cfr. Anexo V) o del Convenio colectivo de Siemens Mobility SLU (BOE de 13 de noviembre de 2020) (cfr. artículo 46bis).

\section{b) Acoso sexual y acoso por razón de sexo, orientación sexual o identidad de género}

Algunos convenios colectivos se limitan a regular tan solo alguna de estas modalidades de acoso. Es más, en ocasiones se realiza una remisión a futuras actuaciones como es el caso del Convenio colectivo de la Industria y Comercio de la Alimentación de Gipuzkoa (BOG de 24 de enero de 2020) que establece que la comisión permanente del convenio en el plazo de un mes a partir de la firma del convenio elaborará un protocolo de actuación en materia de acoso sexual en las relaciones laborales que, una vez aprobado, será distribuido y recomendado a todas las empresas para su utilización como modelo ( $c f r$. artículo 59). En el mismo sentido, pero estableciendo un plazo de tres meses tras la publicación del convenio para la elaboración del protocolo marco de actuación, se pronuncia el IV Convenio colectivo de empresas de personal del transporte de enfermos y accidentados en ambulancia para la comunidad autónoma de Castilla-La Mancha (DOCLM de 11 de febrero de 2020), respecto acoso moral, sexual o por razón de sexo (cfr. artículo 56).

No obstante, abundan los convenios colectivos que contemplan el acoso sexual y el acoso por razón de sexo. Ahora bien, el alcance que se otorga a tales modalidades de acoso varía según los convenios.

Algunos convenios se limitan a ofrecer una definición a los efectos de vigilancia y control, como es el caso del Convenio colectivo de la provincia de Sevilla para las actividades de almacenistas de hierros, tuberías, aceros y material no férreo (BOPS de 8 de junio de 2020) ( $c f r$. Disposición Adicional 5.a). Además, se limita a reproducir las definiciones legales, como sucede en la mayoría de los convenios analizados. Sin embargo, existen convenios que, aun existiendo una definición legal, curiosamente contemplan una definición, aunque similar, diferente de acoso sexual, incorporando incluso las conductas que se consideran constitutivas de dicho acoso. Es lo que sucede en el Convenio colectivo del sector de panaderías de la provincia de Badajoz (DOE de 13 de noviembre de 2020) (cfr. Disposición Adicional primera).

En ocasiones, tales definiciones se contemplan al regular las faltas muy graves, como es el caso del Convenio colectivo provincial de trabajo de la industria siderometalúrgica de Almería (BOPA de 16 de enero de 2020) y del II Convenio colectivo de Compañía Española de Petróleos, SA, para sus refinerías de San Roque (Cádiz); La Rabida (Huelva) y Santa Cruz de Tenerife (BOE de 6 de octubre de 2020).

Otras veces, son los convenios colectivos sectoriales los que, en sintonía con la Ley Orgánica 3/2007, sientan las bases para la regulación de los planes de 
igualdad en las empresas afectadas, determinando así las materias a contemplar y las medidas a adoptar en las mismas. Así, entre dichas materias se recoge la prevención de acoso sexual o acoso por razón de sexo. Es el caso del Convenio colectivo del sector de transportes por carretera del Principado de Asturias (BOPA de 31 de enero de 2020) (cfr. artículo 32).

En la misma línea, hay convenios sectoriales que encomiendan a su comisión paritaria el estudio de un protocolo de acoso sexual, por razón de sexo, orientación sexual e identidad de género para, posteriormente, proponerlo a las empresas del sector para su implantación. Así se hace en el II Convenio colectivo de Compañía Española de Petróleos, SA, para sus refinerías de San Roque (Cádiz); La Rabida (Huelva) y Santa Cruz de Tenerife (BOE de 6 de octubre de 2020) (cfr. artículo 55 y Disposición Transitoria segunda).

También existen convenios sectoriales en los que se crea la obligación para las empresas afectadas de aprobar e implantar un protocolo de actuación en caso de acoso sexual y por razón de sexo, como sucede con el Convenio colectivo para las empresas y las personas trabajadoras de transporte sanitario de enfermos/as y accidentados/as (BOE de 25 de septiembre de 2020) (cfr. artículo 87).

A veces es en la comisión de igualdad de convenio donde se prevé negociar el protocolo, como sucede en el Convenio colectivo nacional del ciclo de comercio de papel y artes gráficas 2019-2021 (BOE de 14 de agosto de 2020) (cfr. 73.2.g). También existen convenios que se remiten a un futuro plan de igualdad que contendrá el protocolo de acoso, como es el caso del Convenio colectivo de Servicios Dix 2012, SL (BOE de 4 de febrero de 2020) (cfr. artículo 35).

Con frecuencia se regula un procedimiento interno de actuación ante el acoso sexual o por razón de sexo. Dicho procedimiento puede variar de contenido, pudiéndose destacar los siguientes: denuncia, apertura de expediente informativo con la creación de una comisión compuesta por personas con la debida formación en la materia, audiencia a todos los implicados y práctica de cuantas diligencias puedan considerarse conducentes a la aclaración de los hechos acaecidos, adopción de medidas cautelares para proteger a la víctima, imposición de sanción en los supuestos de constatación de la existencia de acoso.

De entre la multitud de convenios que se refieren a tales procedimientos pueden consultarse el Convenio colectivo de ámbito estatal para las empresas de mediación de seguros privados para el período 2019-2020 (BOE de 7 de enero de 2020) (cfr. artículo 69), el Convenio colectivo provincial de trabajo de la industria siderometalúrgica de Almería (BOPA de 16 de enero de 2020) (cfr. artículo 60); el Convenio colectivo de la provincia de Alicante de tintorerías, lavanderías y limpieza de ropas (BOPAl de 22 de julio de 2020); o el Convenio colectivo de Accepta Servicios Integrales, SLU (BOE de 30 de julio de 2020) (cfr. artículo 41). 
Algunos convenios, como el VIII Convenio colectivo estatal del corcho (BOE de 14 de mayo de 2020) (cfr. artículo 105), el Convenio colectivo del Grupo Bebidas Naturales (Bebidas Naturales, SL, Aguas de Cortes, SA, Agua de Bronchales, SA, Fuente Arevalillo, SL y Font Teix, SA) (BOE de 1 de agosto de 2020) (cfr. artículo 32) y el Convenio colectivo de Dealz España SL (BOE de 14 de agosto de 2020) (cfr. Capítulo XIII), incluyen ese procedimiento en un protocolo que contiene también una serie de compromisos, una declaración de principios, las correspondientes definiciones, las medidas de prevención. En el sismo sentido, pero incluyendo matizaciones terminológicas respecto a los tipos de acoso sexual, a través de las definiciones de acoso «quid pro quo» o acoso ambiental, profundizando en las garantías para las partes del procedimiento y regulando las posibles represalias contra las víctimas, resulta de interés del Convenio colectivo para las futbolistas que prestan sus servicios en clubes de primera división femenina de fútbol (BOE de 15 de agosto de 2020) (cfr. Anexo II).

Tampoco faltan convenios que regulan normas de comportamiento para prevenir situaciones que favorezcan la aparición de casos de acoso en el trabajo, como sucede con el Convenio colectivo de bebidas refrescantes de la Comunidad Valenciana 2019-2021 (DOGV de 6 de febrero de 2020) (cfr. artículo 47). En ocasiones, se prevén medidas específicas para prevenir el acoso sexual y el acoso por razón de sexo, incluso códigos de conducta, como ocurre con el Convenio colectivo nacional del ciclo de comercio de papel y artes gráficas 2019-2021 (BOE de 14 de agosto de 2020) (cfr. respectivamente el Capítulo XXI y el Anexo I). En este caso en concreto, se recoge el Código de Conducta sobre las medidas para combatir el acoso sexual elaborado por la Comisión de las Comunidades Europeas, en cumplimiento de la Recomendación de dicha Comisión, 1992/131/CEE, de 27 de noviembre, relativa a la protección de la dignidad de la mujer y del hombre en el trabajo.

\section{c) Acoso discriminatorio}

Si bien todo acoso es por sí discriminatorio, algunos convenios se refieren expresamente a esta modalidad de acoso, aludiendo a sus causas, a saber, el origen racial o étnico, el sexo, la religión o convicciones, la discapacidad, la edad o la orientación sexual, así como ofreciendo su definición, en términos parecidos a los legalmente establecidos. Es el caso del Convenio colectivo de recuperación de materiales diversos, SA (BOE de 14 de agosto de 2020) (cfr. artículo 46), del Convenio colectivo de Innometal 2019, SL (BOE de 13 de mayo de 2020) (cfr. artículo 28.D.o) o del Convenio colectivo de EDF-Fenice Ibérica, SLU (BOE de 13 de mayo de 2020) (cfr. Anexo I. artículo 5.ñ).

\section{d) Violencia en el lugar de trabajo}

El Convenio colectivo estatal de estaciones de servicio (BOE de 11 de marzo de 2020) (Anexo 1) contiene una definición de violencia en el lugar de trabajo, 
al señalar que existe dicha violencia cuando una o más personas trabajadoras o directivas son agredidas en el seno de una relación de trabajo.

\section{e) Fatiga}

Entre los convenios que se refieren expresamente a la fatiga se encuentra el Convenio colectivo de limpieza de edificios y locales de la provincia de Teruel (BOPTE de 3 de enero de 2020) (cfr. artículo 28). Concretamente, establece que al organizar el personal se debe prever que los rendimientos sean normales, la limpieza efectiva y, al mismo tiempo, se debe evitar la fatiga de las personas trabajadoras.

Igualmente, se refiere a la fatiga el Convenio colectivo de Air Nostrum LAM, SA (Pilotos) (BOE de 13 de mayo de 2020) (cfr. artículo 14.16), que por mor de la seguridad de los tripulantes, de los viajeros y de las seguridad aérea, dota a los comandantes de la facultad de suspender o aplazar la continuación de un vuelo antes de llegar a los límites establecidos, cuando a su juicio, el estado de fatiga de sí mismo o de algún miembro de la tripulación esencial para la operación de la aeronave así lo exige, hasta que, mediante un período de descanso adecuado, el tripulante o tripulantes se recuperen de su estado de fatiga. La misma pauta se recoge en el III Convenio colectivo de Vueling Airlines, SA, y sus tripulantes pilotos (BOE de 13 de noviembre de 2020) (cfr. artículo 12.26).

Se refiere a la fatiga informática el Convenio colectivo de CTC Externalización, SLU (BOE de 18 de marzo de 2020) (artículo 85), al regular el derecho a la desconexión digital y señalar que la empresa, previa audiencia de los representantes de las personas trabajadoras, elaborará una política interna dirigida a la plantilla, en la que se definirán las acciones de formación y sensibilización del personal sobre un uso razonable de las herramientas tecnológicas que evite el riesgo de fatiga informática. En iguales términos se refiere a la fatiga informática el Convenio colectivo del sector de la Industria, la Tecnología y los Servicios del sector del metal de la provincia de Zaragoza (BOPZ de 13 de noviembre de 2020) (cfr. artículo 46). Por su parte, el Convenio colectivo para las cajas y entidades financieras de ahorro (BOE de 3 de diciembre de 2020) (cfr. artículo 15), también considera que la desconexión digital es un derecho cuya regulación contribuye a la salud de las personas trabajadoras disminuyendo, entre otras, la fatiga tecnológica o estrés.

El Convenio colectivo de Teleinformática y Comunicaciones, SAU (BOE de 22 de junio de 2020) (cfr. Anexo 2) incide en garantizar una formación adecuada para las personas teletrabajadoras, entre otras materias, en cuestiones psicosociales precisas para una correcta adecuación al entorno laboral. No se concreta en qué consisten esas cuestiones psicosociales, pero sí se contienen referencias a la fatiga, por ejemplo, al indicar que se debe cambiar periódicamente la postura para evitar la fatiga, que lo más recomendable desde el punto de vista de 
la salud es utilizar descansos de 5 a 10 minutos cada dos horas de esfuerzo visual continuo para recuperarse de la fatiga visual acumulada. Se establece que la política interna tendrá que contener acciones formativas y campañas de sensibilización sobre la utilización de las herramientas tecnológicas con el objetivo de evitar la fatiga informática.

Indirectamente, algún convenio, como el II Convenio colectivo de Compañía Española de Petróleos, SA, para sus refinerías de San Roque (Cádiz); La Rabida (Huelva) y Santa Cruz de Tenerife (BOE de 6 de octubre de 2020) (cfr. artículo 7.2), relaciona el absentismo con la fatiga, como consecuencia de la misma, al considerar el absentismo un fenómeno complejo relacionado con la salud. Precisamente, para paliarlo se asume el compromiso de adoptar medidas racionales que la legislación y las ciencias médicas y psicosociales permitan.

Aun no refiriéndose expresamente a la fatiga, existen convenios colectivos que regulan medidas conducentes a prevenir que se manifieste. Es el caso del IV Convenio colectivo de empresas de personal del transporte de enfermos y accidentados en ambulancia para la comunidad autónoma de Castilla-La Mancha (DOCLM de 11 de febrero de 2020). Por una parte, establece la obligación de la empresa de facilitar a las personas trabajadoras una herramienta de uso obligatorio, con el fin de registrar la actividad individualizada realizada durante la jornada. Sin duda, se trata de un mecanismo útil para evitar los excesos de jornada (cfr. artículo 28). Por otra parte, se prevé para las bases donde se realicen turnos de 24 horas la existencia de espacios adecuados con dotación propia para el descanso y en los que se cumplan las normas de salud laboral (cfr. artículo 30). Algunos convenios, como el Convenio colectivo del sector Montajes y Empresas Auxiliares del Principado de Asturias (BOPA de 31 de enero de 2020) regulan descansos compensatorios para el personal a turnos con la finalidad de compensar los excesos de jornada que pudieran producirse ( $c f r$. Disposición Adicional tercera). Otros convenios establecen pautas generales que ayudan a evitar la fatiga. Así, el IV Convenio colectivo general del sector de servicios de asistencia en tierra en aeropuertos (BOE de 13 de enero de 2020) (cfr. artículo 34), al referirse al trabajo a turnos y nocturno, establece que cuando se organice el trabajo en la empresa según un cierto ritmo, debe tenerse en cuenta el principio general de adaptación del trabajo a la persona, especialmente de cara a atenuar el trabajo monótono y repetitivo en función del tipo de actividad y de las exigencias en materia de seguridad y salud de las personas trabajadoras. Especialmente, se matiza que dichas exigencias deben ser tenidas en cuenta a la hora de determinar los períodos de descanso durante la jornada de trabajo.

En la misma línea, otros convenios optan por limitar en el tiempo los servicios en régimen de cuatro turnos, como sucede en el Convenio colectivo de bebidas refrescantes de la Comunidad Valenciana 2019-2021 (DOGV de 6 de febrero de 2020) (cfr. artículo 21). 
También resulta interesante observar como algún convenio sectorial, como el Convenio colectivo para las empresas y las personas trabajadoras de transporte sanitario de enfermos/as y accidentados/as (BOE de 25 de septiembre de 2020) (cfr. Disposición Transitoria segunda), respecto a los turnos especiales de emergencia (en guardia presencial o con dispositivo de localización) aboga por establecer e interpretar los tiempos máximos de trabajo efectivo, las horas de presencia y los descansos, para lo que se establecen criterios a tener en cuenta por los convenios de ámbito funcional y/o territorial inferior.

\subsection{Protección genérica frente a riesgos psicosociales}

Algunos convenios colectivos, como el Convenio colectivo de Siemens Halthcare SLU (BOE de 28 de febrero de 2020) o el Convenio colectivo de Siemens Mobility, SLU (BOE de 13 de noviembre de 2020) se limitan a establecer el derecho a la protección adecuada de la integridad física y psicosocial en el marco de una adecuada política de seguridad e higiene en el trabajo (cfr., respectivamente, artículos 35 y 46).

Por otro lado, dentro de los planes de igualdad, comienzan a recogerse medidas que, sin duda, repercutirán positivamente en la protección de los riesgos psicosociales, cuando los mismos estén relacionados con el sesgo de género (supra 3). Es el caso del Convenio colectivo Diario El Correo, SAU año 2020 (BOPV de 10 de diciembre). Así, al regular el plan de igualdad (cfr. Capítulo Décimo), resulta de interés observar cómo la empresa, previamente a la fijación de los objetivos de igualdad, debe realizar un diagnóstico de situación con el objetivo de obtener datos desagregados por sexos en relación con las condiciones de trabajo, y con especial referencia a materias tales como el acceso al empleo, la formación, la clasificación y promoción profesional, las condiciones retributivas y de ordenación de la jornada, de conciliación de la vida laboral, familiar y personal, etc. (cfr. artículo 52).

Con mayor precisión, se señala que el diagnóstico de situación debe proporcionar datos desagregados por sexos en relación, entre otras, con algunas de las siguientes cuestiones: (a) distribución de la plantilla en relación con edades, antigüedad, departamento, nivel jerárquico, grupos profesionales y nivel de formación; (b) distribución de la plantilla en relación con los tipos de contratos; (c) distribución de la plantilla en relación con grupos profesionales y salarios; (d) distribución de la plantilla en relación con la ordenación de la jornada, horas anuales de trabajo y medidas de conciliación de la vida familiar y laboral; (e) niveles de absentismo especificando causas y desglosando las correspondientes a permisos, incapacidades $\mathrm{u}$ otras; ( $\mathrm{f}$ ) excedencias último año y los motivos; (g) promociones último año especificando grupo profesional y puestos a los que se ha promocionado.

Además, se establece que deben diagnosticarse: los criterios y canales de información y/o comunicación utilizados en los procesos de selección, formación y pro- 
moción, los métodos utilizados para la descripción de perfiles profesionales y puestos de trabajo, el lenguaje y contenido de las ofertas de empleo y de los formularios de solicitud para participar en procesos de selección, formación y promoción.

Las conclusiones o resultados obtenidos deben informarse por escrito a los representantes de las personas trabajadoras. En función de todo ello se fijarán los objetivos concretos a alcanzar. Según se prevé (cfr. artículo 53), tales objetivos podrán consistir en el establecimiento de medidas de acción positiva en aquellas cuestiones en las que se haya constatado la existencia de situaciones de desigualdad entre mujeres y hombres carentes de justificación objetiva, así como en el establecimiento de medidas generales para la aplicación efectiva del principio de igualdad de trato y no discriminación. Se especifica, asimismo, que tales objetivos, que incluirán las estrategias y prácticas para su consecución, irán destinados preferentemente a las áreas de acceso al empleo, formación, clasificación y promoción profesional, condiciones retributivas y de jornada, conciliación de la vida familiar, etc., y, entre otros, podrán consistir en: (a) asegurar procedimientos de selección transparente para ingreso en la empresa mediante la redacción y difusión no discriminatoria de las ofertas de empleo y el establecimiento de pruebas objetivas y adecuadas a los requerimientos del puesto ofertado, relacionadas exclusivamente con la valoración de aptitudes y capacidades individuales; (b) promover la inclusión de mujeres en puestos que impliquen mando y/o responsabilidad; (c) establecer programas específicos para la selección/promoción de mujeres en puestos en los que están subrepresentadas; (d) garantizar el acceso en igualdad de hombres y mujeres a la formación de empresa tanto interna como externa, con el fin de garantizar la permanencia en el empleo de las mujeres, desarrollando su nivel formativo y su adaptabilidad a los requisitos de la demanda de empleo; (e) revisar los complementos que componen el salario para verificar que no estén encerrando una discriminación sobre las trabajadoras; (f) promover procesos y establecer plazos para corregir las posibles diferencias salariales existentes entre hombres y mujeres; $(\mathrm{g})$ conseguir una mayor y mejor conciliación de la vida familiar y laboral de hombres y mujeres mediante campañas de sensibilización, difusión de los permisos y excedencias legales existentes, etc.; (h) establecer medidas para detectar y corregir posibles riesgos para la salud de las trabajadoras, en especial de las mujeres embarazadas, así como acciones contra los posibles casos de acoso moral y sexual.

\subsection{Evaluación de riesgos psicosociales}

Algunos convenios colectivos mencionan expresamente los riesgos psicosociales al referirse a la evaluación de riesgos laborales. Sin embargo, el tratamiento de los mismos varía.

El Convenio colectivo estatal de centros de servicios veterinarios (BOE de 14 de agosto de 2020) prevé que la evaluación de riesgos debe tener en cuenta 
los riesgos psicosociales presentes en cada puesto de trabajo (cfr. artículo 58.2). En parecidos términos, el IV Convenio colectivo del Grupo Zena, SL (BOE de 6 de agosto de 2020) señala que las evaluaciones de riesgo contendrán necesariamente un análisis de las condiciones psicosociales derivados del trabajo ( $c f r$. Disposición Adicional tercera). El Convenio colectivo de la provincia de Sevilla para las actividades de almacenistas de hierros, tuberías, aceros y material no férreo (BOPS de 8 de junio de 2020) establece que para llevar a cabo la evaluación de riesgos previamente se debe elaborar un proyecto de recogida de información de todos los riesgos relativos a los puestos de trabajo, incluyendo de forma expresa los psicológicos (cfr. artículo 37).

Aunque sea en el seno del Protocolo de prevención y tratamiento de situaciones de acoso moral y sexual, el IV Convenio colectivo de Movistar+ (DTS, Distribuidora de Televisión Digital, SA; Telefónica Audiovisual Digital, SLU y Compañía Independiente de Televisión, SL) (BOE de 1 de agosto de 2020) ( $c f r$. Disposición Adicional única), recoge que la Dirección establecerá mecanismos de detección de posibles riesgos psicosociales, y en su caso procederá a la evaluación de los mismos. Asimismo, incorporará en las acciones formativas dirigidas a todas las personas trabajadoras información relativa a tales riesgos. Algo parecido sucede en el IV Convenio colectivo del grupo de empresas Distribuidora Internacional de Alimentación, SA, y Dia Retail España, SAU (BOE de 15 de julio de 2020) (cfr. artículo 60), pues, al regular la protección frente al acoso moral, señala que el comité de seguridad y salud establecerá los mecanismos de detección de posibles riesgos psicosociales y, en su caso, se procederá a la evaluación de los mismos, y se promoverá, adicionalmente, la detección precoz de situaciones de riesgo a través de la vigilancia de la salud.

El Convenio colectivo provincial de trabajo de la industria siderometalúrgica de Almería (BOPA de 16 de enero de 2020) incluye en la evaluación de riesgos laborales a los riesgos psicosociales solamente ante indicios razonables de su presencia, concretándose que se entiende por indicios razonables las peticiones trasladadas por el delegado de prevención, o en su caso, el personal integrante del servicio de prevención, o el comité de seguridad y salud, siendo en todo caso informado por escrito el empresario ( $c f r$. artículo 52). En parecidos términos se pronuncia el Convenio colectivo para las industrias de hostelería y turismo de la provincia de Huesca (BOPH de 23 de julio de 2020), con la diferencia de que una vez realizada la petición de evaluación se procederá conjuntamente entre la empresa y los delegados de prevención o la representación de las personas trabajadoras en el comité de prevención laboral y de la salud a analizar las medidas preventivas adecuadas en función de las características de los distintos puestos de trabajo ( $c f r$. artículo 41). Otro tanto contempla el Convenio colectivo del sector Detallistas y Autoservicio de Alimentación de Zaragoza (BOPZ de 16 de septiembre de 2020) (cfr. artículo 43). 
El Convenio colectivo de industrias de conservas y salazones de pescados de la provincia de Huelva (BOH de 25 de junio de 2020) establece que solamente se procederá a la evaluación de los riesgos psicosociales en el ámbito de los casos de acoso sexual y por razón de género, una vez finalizados los procedimientos en los que se constate el acoso (cfr. artículo 39.8).

El Convenio colectivo de Nordex Energy Spain, SAU (centros de Navarra y Castellón) (BOE de 13 de mayo de 2020) al referirse a la evaluación de riesgos incluye expresamente los riesgos relacionados con la psicosociología. Se señala que será la empresa quien efectuará las evaluaciones, teniendo en cuenta, con carácter general, la naturaleza de la actividad, las características de los puestos de trabajo y de las personas trabajadoras que deban desempeñarlos. Tan solo se reconoce el derecho a que puedan participar en dichas evaluaciones los delegados de prevención del centro de trabajo o, en su defecto, los delegados de prevención integrantes de los comités de seguridad y salud laboral (cfr. artículo 67).

El Convenio colectivo de Lyntia Networks, SAU., para los centros de trabajo de Madrid y A Coruña (BOE de 23 de noviembre de 2020) matiza que dentro de la evaluación de los riesgos laborales existen los riesgos psicosociales y recuerda que estos deben ser evaluados con la misma intensidad que el resto de riesgos identificados de la empresa. Además, precisa que a tal efecto el método de evaluación elegido debe ser consensuado en el comité de seguridad y salud, o con los delegados de prevención en su lugar, debe favorecer la participación y deber ser un método científicamente probado (cfr. artículo 55).

El IV Convenio colectivo del grupo VIPS (BOE de 14 de agosto de 2020) aboga por la colaboración entre la empresa y la representación legal de las personas trabajadoras en la atención a los riesgos psicosociales. Para ello ambas partes pueden compartir la realización de encuentras puntuales de clima laboral para la detección entre otras cuestiones de dichos riesgos y para proponer en su caso medidas tendentes a su corrección. Igualmente, la colaboración se llevará a cabo en la realización de las pertinentes auditorías y en la concienciación de las personas trabajadoras en el seguimiento y cumplimiento de las medidas de seguridad. Con todo ello se pretende el aseguramiento de un sistema de prevención de riesgos laborales y la integración en el mismo de las personas trabajadoras. En todo caso, se reconoce expresamente que las evaluaciones de riesgo contendrán necesariamente un análisis de las condiciones de trabajo desde el punto de vista de los factores psicosociales derivados del trabajo ( $\mathrm{frr}$. Disposición Adicional cuarta).

El II Convenio colectivo del Grupo ASV Servicios Funerarios (BOE de 17 de junio de 2020) dispone que en materia de psicosociología aplicada serán de aplicación las normas y disposiciones sobre evaluación de riesgos psicosociales que tiene establecidas o pueda establecer el INSHT ( $c f r$. artículo 76.2.i). 
El V Convenio colectivo marco del Grupo Endesa (BOE de 17 de junio de 2020), al referirse a la vigilancia de la salud establece que la empresa prestará especial atención a la detección y evaluación de los riesgos psicosociales, así como a la aplicación de las medidas preventivas y/o correctoras oportunas (cfr. artículo 113.5). Además, al abordar los principios generales, en materia de prevención de riesgos laborales, establece que, con el objetivo de lograr una mayor eficacia en la prevención de riesgos psicosociales, las partes firmantes del convenio se comprometen a desarrollar en un plazo límite de un año posterior a la firma del convenio, un «Protocolo de riesgos psicosociales» que tendrá como base los siguientes principios: (a) tener un enfoque proactivo, es decir, se debe activar por la detección de indicadores de riesgos; (b) incorporar medidas concretas de prevención y de detección precoz mediante el tratamiento de los indicadores de riesgos; (c) desarrollar medidas para paliar los riesgos detectados ( $c f r$. artículo 110.6).

\subsection{Organización de la prevención y riesgos psicosociales}

Muchos convenios apuestan por organizar la prevención a través de un Servicio de Prevención Propio, y al determinar las funciones y niveles de cualificación del mismo especifican que se contratará a personal técnico superior especializado, entre otras ciencias o técnicas preventivas en psicosociología. Así sucede, por ejemplo, en el II Convenio colectivo de Compañía Española de Petróleos, SA, para sus refinerías de San Roque (Cádiz); La Rabida (Huelva) y Santa Cruz de Tenerife (BOE de 6 de octubre de 2020) (cfr. Apartado IX, subapartado 6). Por su parte, el Convenio colectivo de Nordex Energy Spain, SAU (centros de Navarra y Castellón (BOE de 13 de mayo de 2020) (cfr. artículo 60) se limita a señalar que su Servicio de Prevención Propio asumirá, entre otras especialidades, la correspondiente a la psicosociología aplicada. En un grado de mayor detalle, el Convenio colectivo de CEPL Iberia, SL (BOE de 19 de agosto de 2020) (cfr. artículo 51.1.2) especifica que los servicios de prevención deben proporcionar a la empresa, a las personas trabajadoras y a sus representantes y a los órganos de representación especializada el asesoramiento y apoyo que se precise en función de los riesgos existentes, y en relación con la evaluación de los factores de riesgos, incluyendo la evaluación de los riesgos psicosociales. En parecidos términos se pronuncia el Convenio colectivo de Compañía Auxiliar al Cargo Express, SA (BOE de 11 de julio de 2020) ( $c f r$. artículo 40), al señalar que las evaluaciones de riesgo se realizarán por el Servicio de Prevención o por las personas trabajadoras designadas por la empresa, de acuerdo con el procedimiento consensuado en el comité de seguridad y salud o con los delegados de prevención.

Algún convenio, como el Convenio colectivo de Bridgestone Hispania Manufacturing, SL (BOE de 14 de agosto de 2020) (cfr. artículo 186) prevé la existencia de un servicio psicosociológico en su Servicio de Prevención, pero contiene la doble posibilidad de contratar profesionales o una entidad externa especializada en psicosociología para cubrir esa prestación de manera adecuada. 


\section{Conclusiones}

Primera. No existe en la legislación española un concepto de riesgo psicosocial pero sí existen conceptos técnicos bien determinados que pueden ser tomados en consideración por la negociación colectiva.

Segunda. La identificación de factores sociales en la organización del trabajo facilita la concreción de los riesgos psicosociales que pueden existir en un sector o en una empresa, para su evaluación y tratamiento en la planificación de la actividad preventiva. A tal efecto resulta esencial tener en cuenta las NTP del INSHT.

Tercera. Existe consenso sobre la consideración como riesgo psicosocial del estrés laboral, la violencia en el trabajo, la fatiga de las personas trabajadoras y el burnout o síndrome de estar quemado por el trabajo. Aunque cuentan con un menor reconocimiento también se consideran riesgos psicosociales la ambigüedad y conflicto de rol, el trabajo emocional y la adicción al trabajo.

Cuarta. Existe una definición clara de estrés laboral. Igualmente, las NTP del INSHT han definido sus variantes derivadas de uso de las TIC, dentro de lo que viene denominándose tecnoestrés, a saber, la tecnoansiedad, la tecnofobia y la tecnoadicción.

Quinta. Debe diferenciarse del estrés laboral el burnout o síndrome de estar quemado por el trabajo. Respecto a esta última también puede considerarse la definición dada por las NTP del INSHT.

Sexta. No existe una definición legal de violencia en el trabajo. No obstante, a partir de las características que presenta en el Convenio OIT núm. 190, es posible acotar su significado, teniendo en cuenta las manifestaciones de la misma. De este modo, se ajustan a dichas características las definiciones legales de acoso discriminatorio, acoso por razón de discapacidad, acoso sexual y acoso por razón de sexo. Al no existir una definición legal de acoso moral en el trabajo, debieran reformularse las diversas definiciones utilizadas hasta la fecha por no ajustarse a las características que presenta el concepto de violencia en el trabajo en el Convenio OIT núm. 190. En ese sentido, los criterios fijados por la STC 56/2019 constituyen un punto de partida adecuado. Respecto al concepto de violencia en el lugar del trabajo, diferenciado de las distintas variantes de acoso, falta un concepto legal pero sí existe una interesante definición en la NTP 489 del INSHT.

Séptima. Tampoco existe una definición de fatiga de las personas trabajadoras, pero existen distintos criterios técnicos, principalmente los fijados en las NTP del INSHT, que ayudan a caracterizarla. Conforme a dichos criterios la carga mental del trabajo constituye una modalidad de fatiga. Además, los trabajos basados en la utilización de las TIC pueden provocar una variante de fatiga, a saber, la tecnofatiga, siendo uno de sus tipos más comunes la fatiga informativa. 
Octava. Los conceptos de ambigüedad y conflicto de rol, de trabajo emocional y de adición al trabajo también carecen de definición legal y hay que estar a los criterios fijados por las NTP del INSHT para poder comprender su alcance como riesgos psicosociales.

Novena. Las posibilidades regulatorias de la negociación colectiva en materia de prevención de riesgos psicosociales se producen a partir del respeto al suelo mínimo que suponen la LPRL y sus reglamentos de desarrollo, pero también a partir del respeto a otras normas como la Ley Orgánica 3/2007 o el Real Decreto 901/2020. Los fundamentos jurídicos que contienen todas esas normas, así como los vacíos normativos respecto al tratamiento específicos de los riesgos psicosociales, permiten a la negociación colectiva, entre otras cuestiones, definir los riesgos psicosociales; identificar los posibles riesgos psicosociales para su evaluación posterior; establecer los correspondientes protocolos de actuación y medidas disuasorias; concretar la participación de las personas trabajadoras en la planificación de la prevención; regular la información y formación de las personas trabajadoras en materia de riesgos psicosociales; apostar por que la organización preventiva se lleve a cabo por la propia empresa y, siempre que se pueda, por los servicios de prevención propios; posibilitar que la organización preventiva asuma actividades preventivas relacionadas con los riesgos psicosociales; establecer reconocimientos médicos obligatorios para prevenir las resultas de los riesgos psicosociales en la salud de las personas trabajadoras; regular el modelo de autoría a llevar cabo sobre el sistema de prevención; y prever mecanismos de compliance laboral para prevenir los riesgos que conlleva el incumplimiento de medidas preventivas en materia de riesgos psicosociales.

Décima. Un análisis de 186 convenios colectivos de distintos ámbitos publicados entre enero y diciembre de 2020 demuestra que:

a) No se define lo que es un riesgo psicosocial.

b) Aunque sin referirse expresamente a los riesgos psicosociales, existen convenios que prevén, dentro de los planes de igualdad, elementos de interés para evitar que el sesgo de género se convierta en riesgo psicosocial.

c) El acoso psicológico o moral, el acoso sexual y el acoso por razón de sexo son los riesgos psicosociales que más se contemplan. La fatiga se regula principalmente en concretos ámbitos como los relacionados con la aviación y los trabajos tecnológicos. La violencia en el trabajo se define en un único convenio y otro tanto sucede con el burnout o síndrome del quemado en el trabajo.

d) Respecto al acoso moral en el trabajo es frecuente que se defina, aunque todavía sin ajustarse al Convenio OIT núm. 190; a veces se concretan las conductas que se consideran constitutivas de acoso moral, y es habitual que se regule un protocolo para combatirlo. En ocasiones dicho protocolo es genérico para cualquier tipo de acoso. 
e) El acoso sexual y el acoso por razón de sexo son los riesgos psicosociales más tratados, aunque con distinto alcance. Algunos convenios se limitan a definirlos para su vigilancia y control. No obstante, otros convenios se remiten a los planes de igualdad para regular la prevención de estas modalidades de acoso, prevén o regulan procedimientos y/o protocolos de actuación, y regulan normas de comportamiento y códigos de conducta para prevenir situaciones que favorezcan la aparición de casos de acoso.

f) Existen convenios que se limitan a reconocer el derecho a la integridad física y psicosocial, sin concreción alguna al respecto.

g) Aunque los riesgos psicosociales deben ser evaluados como cualquier otro riesgo, algunos convenios se refieren expresamente a la evaluación de tales riesgos. Incluso algunos convenios establecen condiciones para ello o limitan la evaluación a determinados riesgos psicosociales como el acoso sexual o por razón de género. Sin embargo, son pocos los convenios que van más allá, por ejemplo, para incidir en la forma o el método para llevar a cabo la evaluación, en la participación de los representantes de las personas trabajadoras o en la información y formación de las personas trabajadoras en materia de riesgos psicosociales. Aun así, debe destacarse el compromiso asumido en un concreto convenio para la elaboración de un protocolo de riesgos psicosociales.

h) En materia de organización de la prevención son muchos los convenios que apuestan por un Servicio de Prevención Propio y que, aunque con distinto alcance, incorporan aspectos relacionados con los riesgos psicosociales, a partir de la asunción de la especialidad de psicosociología como ciencia o técnica preventiva.

\section{Bibliografía}

Arastey SAhún, María Lourdes (2012): «Los riesgos psicosociales en la apreciación de los tribunales: algunas cuestiones sobre la aplicación práctica de la Directiva marco 1989/391/CEE, Relaciones Laborales, 11, 1-15 (LA LEY 5987/2012).

Botana López, José María (1997): «Objeto, ámbito de aplicación y definiciones», en Iglesias Cabero, Manuel (coord.), Comentarios a la Ley de Prevención de Riesgos Laborales. Madrid: Civitas, 27-42.

Charro Baena, Pilar (2012): «La organización del trabajo como factor de riesgo psicosocial", Revista del Ministerio de Empleo y Seguridad Social, 98, 15-29.

Ficha Técnica de Prevención 35 del INSL (2011): Mujeres y Salud Laboral. Prevención de riesgos laborales desde la perspectiva de género. Propuestas de intervención.

GoÑI SeIN, José Luis (2013): «Las funciones del convenio colectivo en el desarrollo de la prevención de riesgos laborales», en Ramos Quintana, Margarita Isabel (dir.), Salud en el trabajo y riesgos laborales emergentes. Albacete: Bomarzo, 45-55. 
Grau Pineda, Carmen (2017): «Sobre la imperiosa necesidad de incorporar el sesgo de género en la gestión de los riesgos psicosociales», Estudios Financieros. Revista de Trabajo y Seguridad Social. Comentarios, casos prácticos: recursos humanos, 23-58.

Igartua Miró, María Teresa (2017): «Los riesgos psicosociales: evaluación y prevención. El caso Caixabank», Trabajo y Derecho, 27, 1-21 (LA LEY 1757/2017).

ITSS (20 1 2): Guia de actuaciones de la Inspección de Trabajo y Seguridad Social sobre Riesgos Psicosociales, I-56.

Norma ISO I0075 (199I): Principios ergonómicos relacionados con la carga de trabajo mental.

Martín Valverde, Antonio (2009): «Acoso en el trabajo», en Sempere Navarro, Antonio Vicente, Pérez de los Cobos Orinuel, Francisco. y Aguilera Izquierdo, Raquel. (dirs.), Enciclopedia Laboral Básica "Alfredo Montoya Melgar». Madrid: Civitas, xxx.

Martínez IŃIgo, David (2001): «Evolución del concepto de trabajo emocional: dimensiones, antecedentes y consecuencias. Una revisión teórica», Revista de Psicología del Trabajo y de las Organizaciones, vol. 7, 2, 131-153.

Meléndez Morillo-Velarde, Lourdes (2016): «Nuevas tecnologías y riesgos psicosociales», Civitas: Revista Española de Derecho del Trabajo, 184, 1-30 (BIB 20161704).

Meliá, José Luis; Nogareda, Clotilde; Lahera, Matilde; Duro, Antonio; Peiró, José M.; Salanova, Marisa; y Gracia, Diego (2006): «Principios comunes para la evaluación de los riesgos psicosociales en la empresa», en Perspectivas de Intervención en Riesgos Psicosociales. Evaluación de Riesgos. Barcelona: Foment de Treball Nacional, 16-36.

Mella Méndez, Lourdes (2015): «La seguridad y salud en el teletrabajo», en Mella MÉndez, Lourdes (ed.), Trabajo a distancia y teletrabajo. Estudios sobre su régimen jurídico en el Derecho español y comparado. Cizur Menor: Aranzadi - Thomson Reuters, 171-207.

Mercader Uguina, Jesús Rafael y Muñoz Ruiz, Ana Belén (2002). «El futuro de la negociación colectiva en materia de prevención de riesgos laborales», Revista Doctrinal Aranzadi Social, 14, 1-18 (BIB 2002\1979).

Navarro Moros, María José y Salazar Val, María Dolores (2016): "Los riesgos psicosociales», en Toscani Giménez, Daniel y Alegre Nueno, Manuel (dirs.), Análisis práctico de la Ley de Prevención de Riesgos Laborales. Valladolid: Lex Nova - Thomson Reuters, 117-139.

NTP I79 DEL INSHT (I986): La carga mental del trabajo: definición y evaluación, 1-6.

NTP 388 DEL INSHT (1995): Ambigüedad y conflicto de rol, 1-7.

NTP 443 DEL INSHT (1997): Factores psicosociales: metodología de evaluación, 1-5.

NTP 445 DEL INSHT (1997): Carga mental de trabajo: fatiga, 1-5.

NTP 455 DEL INSHT (I 997): Trabajo a turnos y nocturno: aspectos organizativos, 1-10.

NTP 489 DEL INSHT (I998): Violencia en el lugar de trabajo, 1-8.

NTP 534 DEL INSHT (1999): Carga mental del trabajo: factores, 1-6.

NTP 544 DEL INSHT (2000): Estimación de la carga mental de trabajo: el método NASA $T L X$.

NTP 604 DEL INSHT (200I): Riesgo psicosocial: el modelo demanda-control-apoyo social (II), 1-8.

NTP 704 DEL INSHT (2005): Síndrome de estar quemada por el trabajo o «burnout» (I): definición y proceso de generación, 1-7.

NTP 705 DEL INSHT (2005): Sindrome de estar quemado por el trabajo o burnout»(II): consecuencias, evaluación y prevención, 1-7.

NTP 720 DEL INSHT (2006): El trabajo emocional: concepto y prevención, 1-5. 
NTP 730 (2006) DEL INSHT: Tecnoestrés: concepto, medida e intervención psicosocial, 1-7.

NTP 732 DEL INSHT (2006): Sindrome de estar quemado por el trabajo "Burnout» (III): Instrumento de medición, 1-4.

NTP 759 DEL INSHT (2007): La adicción al trabajo, 1-6.

NTP 854 DEL INSHT (2009): Acoso psicológico en el trabajo: definición, 1-6.

NTP 9I 6 DEL INSHT (20 I I): El descanso en el trabajo (I): pausas, 1-8.

NTP 926 DEL INSHT (201 2): Factores psicosociales: metodología de evaluación, 1-6.

NTP 944 DEL INSHT (2012): Intervención psicosocial en prevención de riesgos laborales: principios comunes (I), 1-4.

NTP I.I23 DEL INSHT (2018): Las Tecnologías de la Información y la Comunicación (TIC) III: factores de riesgo psicosocial asociados a las nuevas formas de organización del trabajo, 1-8.

Pons Carmena, María (2020): «Aproximación a los nuevos conceptos sobre violencia y acoso en el trabajo a partir de la aprobación del Convenio OIT 190», Labos: Revista de Derecho del Trabajo y Protección Social, vol. 1, 2, 30-60.

Quirós Hidalgo, José Gustavo y Álvarez Cuesta, Henar (2010): «Precisiones conceptuales sobre los riesgos psicosociales», en La tutela reparadora de los riesgos psicosociales. Lisboa, Editorial Juruá, 25-60.

Rojas Rosco, Raul, Moraleja Moraleja, Erika y Gutiérrez Arranz, Roberto (2017): Compliance Laboral. Madrid: Francis Lefebvre.

Romeral Hernández, Josefa (2012): «Los riesgos psicosociales en la negociación colectiva", Revista del Ministerio de Empleo y Seguridad Social, 98, 165-188.

Triguero Martínez, Luis Ángel (2019): «Trabajo decente y call centers: salud laboral y riesgos psicosociales en jaque», Revista Internacional y Comparada de Relaciones Laborales y Derecho del Empleo, vol. 7, 4, 42-63.

VAllejo DA Costa, Ruth (2014): «El conflicto trabajo-familia como riesgo psicosocial: su particular incidencia en la mujer trabajadora (aspectos jurídicos)", Estudios Financieros. Revista de Trabajo y Seguridad Social. Comentarios, casos prácticos: recursos humanos, 13-46.

Velázquez Fernández, M.P. (2019): «Riesgos psicosociales e igualdad. La progresiva tendencia hacia la integración de ambas políticas", Estudios Financieros. Revista de Trabajo y Seguridad Social. Comentarios, casos prácticos: recursos humanos, 131-152.

Viñas Armada, José María (2007): Formación básica en prevención de riesgos laborales. Valladolid: Lex Nova. 